\title{
Intermittent Versus Daily Pulmonary Tuberculosis Treatment Regimens: A Meta-Analysis
}

\author{
Samuel Kasozi, MBchB, MIPH; Justin Clark, BA, Lib Tech; and \\ Suhail A.R. Doi, MBBS, FRCP, MClinEpid, PhD
}

\begin{abstract}
Background: Several systematic reviews suggest that intermittent pulmonary tuberculosis (TB) chemotherapy is effective, but intensity (daily versus intermittent) and duration of rifampicin use (intensive phase only versus both phases) have not been distinguished. In addition, the various outcomes (success, failure, relapse, and default) have only selectively been evaluated.

Methods: We conducted a meta-analysis of proportions using all four outcomes as multi-category proportions to examine the effectiveness of WHO category I TB treatment regimens. Database searches of studies reporting treatment outcomes of HIV negative subjects were included and stratified by intensity of therapy and duration of rifampicin therapy. Using a bias-adjusted statistical model, we pooled proportions of the four treatment outcome categories using a method that handles multi-category proportions.

Results: A total of 27 studies comprising of 48 data sets with 10,624 participants were studied. Overall, treatment success was similar among patients treated with intermittent $(\mathrm{I} / \mathrm{l})(88 \%)(95 \% \mathrm{Cl}$, $8 \mathrm{I}-92)$ and daily (D/D) $(90 \%)(95 \% \mathrm{Cl}, 84-95)$ regimens. Default was significantly less with $\mathrm{I} / \mathrm{I}(0 \%)(95 \%$ $\mathrm{Cl}, 0-2)$ compared to D/D regimens $(5 \%)(95 \% \mathrm{Cl}, \mathrm{I}-9)$. Nevertheless, I/l relapse rates $(7 \%)(95 \% \mathrm{Cl}$, $3-\mathrm{II})$ were higher than D/D relapse rates (I\%) $(95 \% \mathrm{Cl}, 0-3)$.

Conclusion: Treatment regimens that are offered completely intermittently versus completely daily are associated with a trade-off between treatment relapse and treatment default. There is a possibility that $\mathrm{I} / \mathrm{I}$ regimens can be improved by increasing treatment duration, and this needs to be urgently addressed by future studies.
\end{abstract}

Keywords: Pulmonary tuberculosis; Chemotherapy; Intermittent; Daily

$\mathrm{T}$ uberculosis (TB) remains a global public health problem despite the presence of effective TB pharmacotherapy for more than 50 years and the use of vaccines for more than 90 years. The situation is further compounded by the global HIV pandemic, which has led to unprecedented increases in both TB incidence and mortality in many areas. Consequently, TB treatment programs are faced with high numbers of TB cases coupled with an increase in unfavorable treatment outcomes among patients undergoing TB treatment. The increasing unfavorable TB treatment outcomes are attributed to poor compliance and adherence to TB treatment secondary to high pill burden, toxicity, and adverse reactions, as well as treatment inconvenience, among other factors. ${ }^{1}$ To mitigate this, intermittent TB treatment regimens have been proposed, and evidence suggests that they achieve a similar treatment outcome to daily regimens. ${ }^{2,3}$

Today, tuberculosis treatment utilizes four key drugs: ethambutol (E), isoniazid (H), rifampicin (R), and Pyrazinamide ( $\mathrm{Z})$. Treatment is in two phases: an initial
Corresponding Author: Dr. Samuel Kasozi;

Makerere University School of Public Health; Ekobo Rd, Kololo Kampala, Central +256; UGANDA; Tel: +256772674536; Mobile:

+256701674536; Email: drsamuelkasozi@gmail.com
Received: January 17, 2015

Revised: April 16, 2015

Accepted: May 15, 2015

doi: $10.3121 / \mathrm{cmr} .2015 .1272$ 


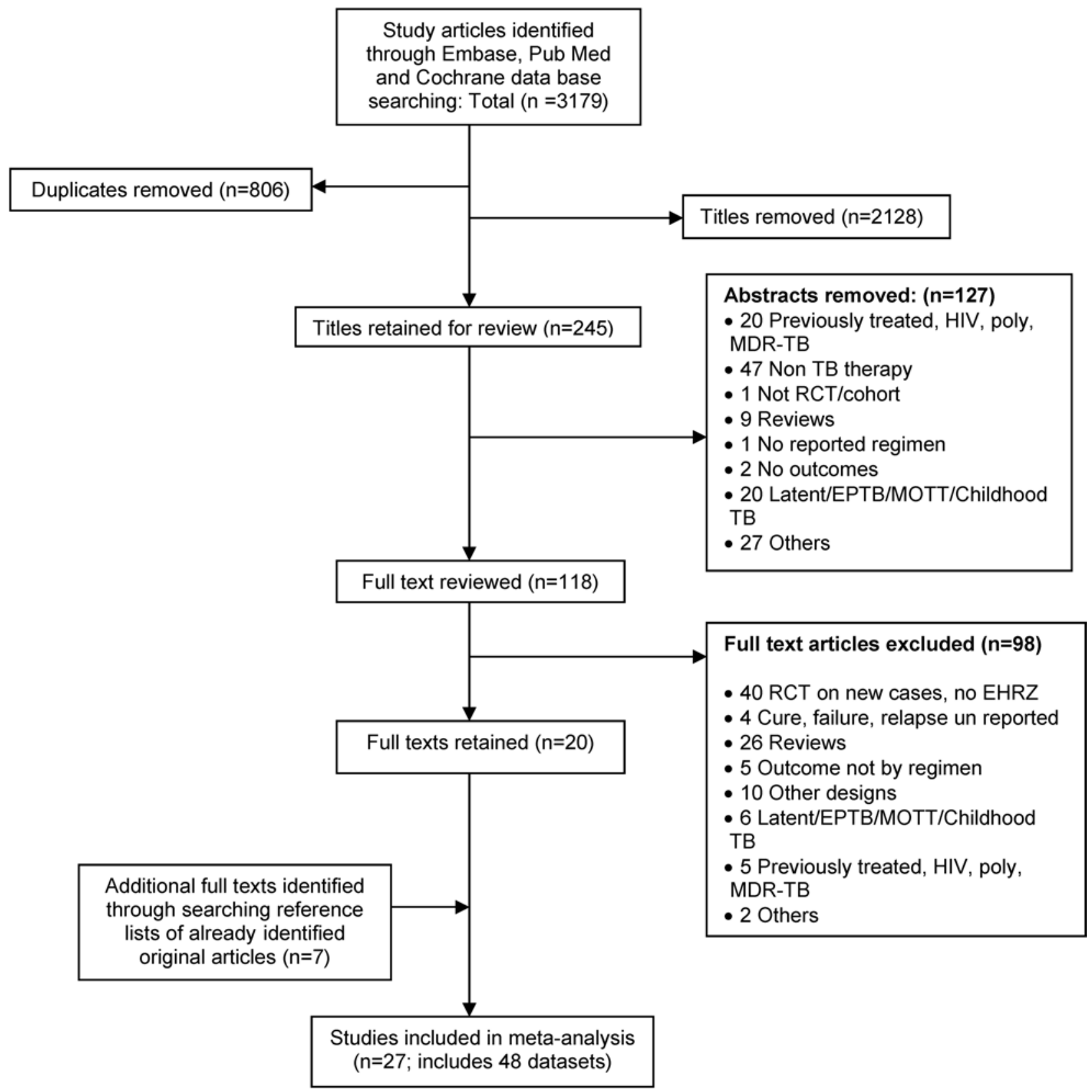

Figure1. Summary of literature search and selection of studies.

intensive phase (IP) and a continuation phase (CP). In this paper, the phases are indicated by a slash, and thus 2HRZE/4RH represents 2 months in the intensive phase and 4 months in the continuation phase with drugs used in each phase denoted as letters. Currently, the World Health Organization (WHO) has recommended the discontinuation of the use of the 8-month treatment regimen that includes only 2 months of rifampicin treatment (2HRZE/6EH) in preference to a 6-month treatment regimen with rifampicin in all 6 months $(2 \mathrm{HRZE} / 4 \mathrm{RH}){ }^{4}{ }^{4}$ In addition, the WHO recommends that this TB treatment regimen (2HRZE/4RH) be administered daily, especially in the IP, except where this daily treatment is not possible. In the latter instance, three times weekly dosing is then allowed. ${ }^{4}$
There is currently no strong evidence that implementation of these daily versus intermittent regimens leads to decreases in treatment failure or relapses, but they certainly are inconvenient and may lead to non-compliance and subsequent drug resistance. Indeed, the number of multi-drug resistant TB (MDR-TB) cases notified by the 27 high burden countries is on the increase and reached 600,000 cases globally in 2011. ${ }^{5}$ This increase in number of MDR-TB cases requires an investigation into the effectiveness of current TB treatment regimens as well their dosing frequencies. Two systematic reviews ${ }^{3,6}$ undertaken to look into this were limited by methodology, with neither looking at all outcome categories or stratifying treatment intensity (daily versus intermittent) by rifampicin use in the IP alone versus both phases. Conclusions 
thus remain uncertain, and given that the basis of the 2010 WHO recommendations was the last review in $2009,{ }^{3}$ and there are now more studies that have been published, we set out to compare the effectiveness of WHO category $1 \mathrm{~TB}$ treatment regimens containing EHRZ in the IP offered either daily (D) throughout or intermittently (I) two-three times per week throughout, stratified according to use of rifampicin in either IP alone or in both phases. We also used a more robust methodology for the meta-analysis of proportions. ${ }^{7}$

\section{Methodology}

\section{Search Strategy}

Three electronic databases — Embase, PubMed, and Cochrane CENTRAL - were searched for studies on treatment of active pulmonary tuberculosis (TB). The search for studies was restricted to studies published in English spanning from 1965 to 2013. The following search terms were used: (Tuberculosis OR Koch's disease) AND (Therapeutics OR Therapeutic OR Therapy) AND (Treatment outcome OR Effectiveness OR Efficacy OR Failure OR Drug resistance) AND (Isoniazid OR Pyrazinamide OR Rifampicin OR Ethambutol). We identified further studies through searching related citations of identified original articles on PubMed. A detailed search string is provided in the supplementary material.

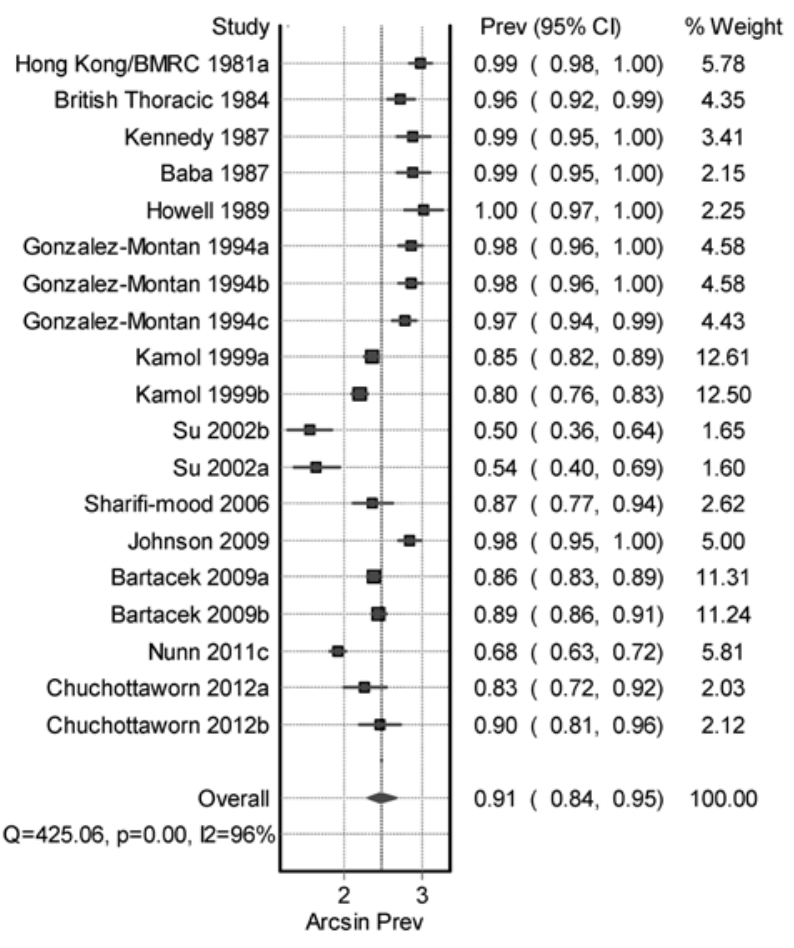

\section{Study Selection}

We conducted a three staged study selection that was done independently by two investigators (figure 1). The selection considered article titles, then abstracts, and finally full text articles, after which comparisons were made and resolution of disagreements reached through discussion and consensus by a third investigator. The selection included original articles of studies that reported treatment outcomes of HIV negative, new drug susceptible, smear positive pulmonary TB patients who were bacteriologically confirmed by sputum smear or culture at both the start and end of the treatment period. Only TB patients treated with WHO Category 1 standard 5-8 months duration regimens containing 2 months of EHRZ in the IP were included. We excluded studies with smear negative TB, extra-pulmonary TB, unconfirmed TB, HIV sero-positive patients, and studies with patients treated with regimens other than WHO Category 1 standard regimens (without EHRZ in IP) or regimens with rifapentine and infrequent therapy such as those with once weekly dosing. We stratified our analyses by regimens that used rifampicin in both phases versus regimens that used rifampicin only in the IP.

Data Extraction and Quality Assessment

Two investigators working independently reviewed all identified and selected studies while resolving data differences

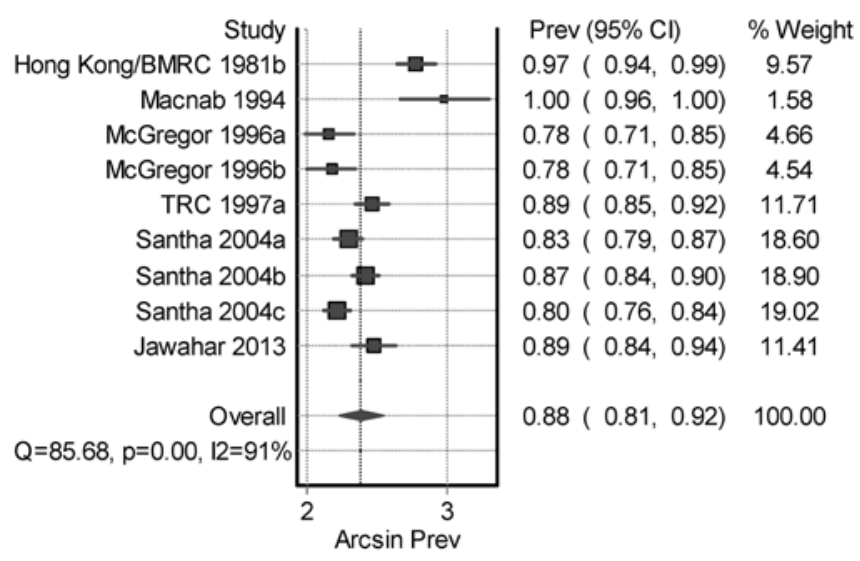

Figure 2. Forest plot of daily* (left) and intermittent* (right) regimen success (Rifampicin throughout).

*These subjects had either the intermittent or daily therapy with Rifampicin throughout both phases of TB therapy. Horizontal lines represent 95\% CI for the studies, box size depicts the study weight and diamond depicts the confidence interval of the pooled estimate. 

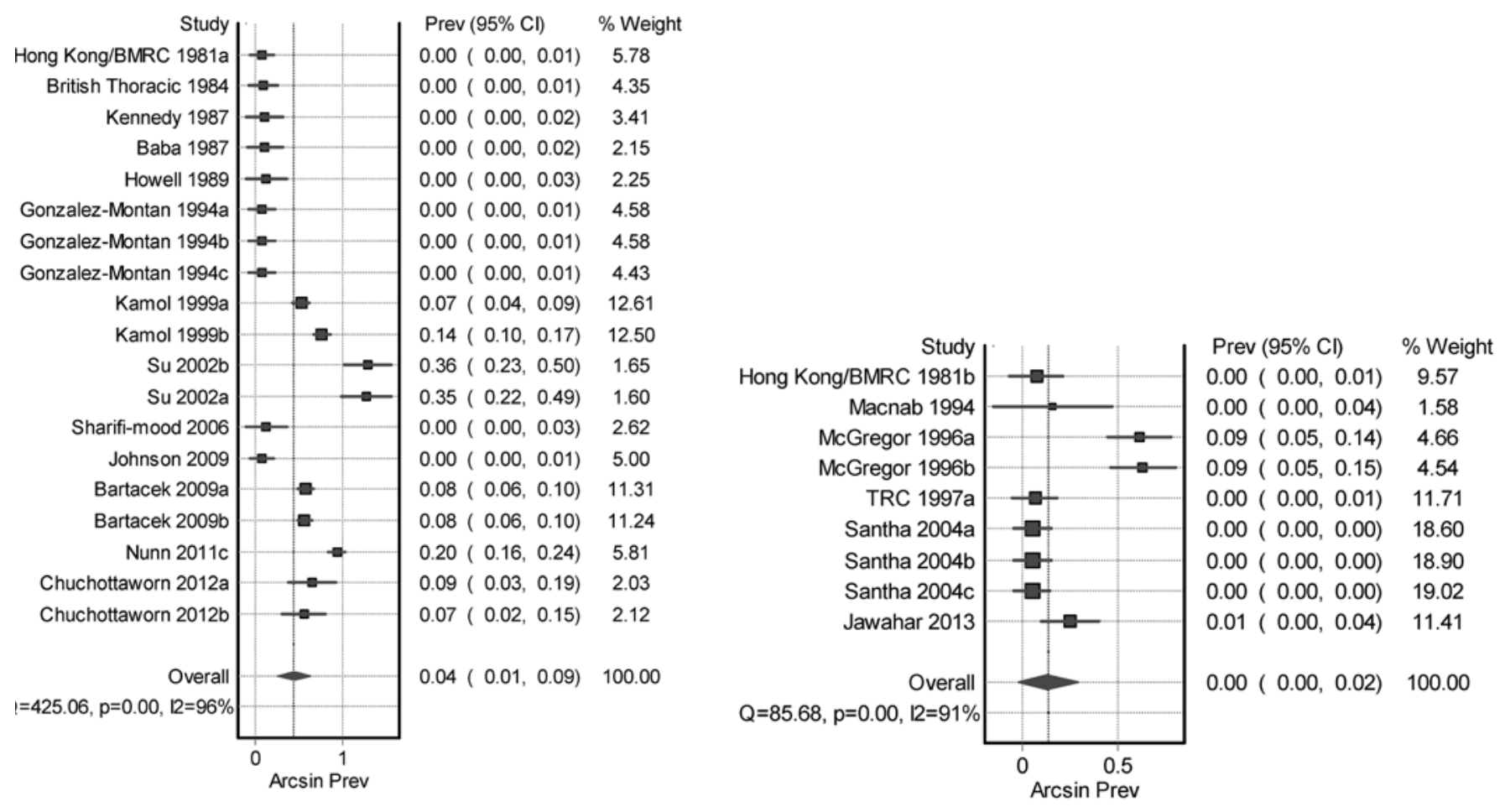

Figure 3. Forest plot of daily* (left) and intermittent* (right) regimen defaulters (Rifampicin throughout).

*These subjects had either the intermittent or daily therapy with Rifampicin throughout both phases of TB therapy. Horizontal lines represent $95 \%$ CI for the studies, box size depicts the study weight and diamond depicts the confidence interval of the pooled estimate.

through discussion and reaching consensus using a third investigator. We then extracted data from selected studies that met the study criteria on patient population and characteristics, number of patients started on treatment, pre- and posttreatment bacteriological results (smear and culture), treatment regimens, supervision of treatment (through directly observed therapy [DOT]) and treatment outcomes. The treatment outcomes of interest were in four categories: treatment success, failed, relapsed, and defaulted (see definitions below).

Quality of study information was ensured by assessing all included studies using a standardized quality assessment form. The quality assessment scheme was modified from that suggested by Hoy et $\mathrm{al}^{8}{ }^{8}$ which is a validated quality assessment checklist (also see supplementary material online). Once assessed, each study was awarded a univariate summary score from all parameters assessed. The total score for each study was then applied to assign weights for each study included in this meta-analysis. If a study contributed more than one dataset, each had the same quality score assigned. This model of meta-analysis does not assume that quality information quantifies either the magnitude or the direction of bias. The ranking of the studies by quality is used to compute a synthetic bias variance that then increases uncertainty around estimates for lower ranked studies. ${ }^{9}$

\section{Outcome Definitions and Exclusions}

TB case and treatment outcome definitions of the WHO were used to classify $\mathrm{TB}$ cases and to determine treatment outcomes. ${ }^{5,10-12} \mathrm{~A}$ new case was defined as a TB patient who had never been on TB treatment before or had ever been on TB treatment but for less than one month. A pulmonary TB case was defined as a TB patient with TB disease involving the lung parenchyma. Regarding treatment outcomes, successfully treated was defined as a combination of completed and cured TB patients. Cure was defined as a patient who was initially bacteriologically positive and who was bacteriologically negative in the last months of treatment and on at least one previous occasion while completed treatment was defined as a patient who completed the standard TB treatment but lacks bacteriological results at the end of treatment. For purposes of this study, a failure was defined as a TB patient who remains or becomes bacteriologically positive at 5 or more months of standard TB treatment or who dies during TB treatment. Relapse was defined as a TB patient who becomes bacteriologically positive after being declared cured at end of TB treatment while a defaulter/loss to follow-up is a TB patient who interrupted TB treatment for 2 or more months after being on treatment for more than one month. Patients who could not be categorized as cured, completed, failed, relapsed, or defaulted based on the above definitions, or if they were transferred to another reporting unit (health facility or district) during 
treatment or for whom treatment outcome was unknown, were excluded from analysis.

\section{Data Synthesis and Analysis}

In all the studies, multi-category proportions of successfully treated, failure, relapse, and default/loss to follow-up were computed as separate categories and pooled simultaneously. Analyses were done separately for regimens with rifampicin in all phases versus rifampicin in IP only. The primary outcome of interest was the proportions of these four outcomes in those receiving completely intermittent (I/I) or completely daily $(\mathrm{D} / \mathrm{D})$ treatment. The secondary outcomes were those for mixed regimens that used daily therapy in one phase and intermittent in the other or regimens that used rifampicin only in the IP.

We used the quality effects mode ${ }^{13}$ to pool the categorical proportions and report the overall pooled estimate of the various outcome categories. We chose the quality effects model over the conventional random effects model based on the fact that the model incorporates quality of studies in the analysis of the overall intervention efficacy, ${ }^{13}$ thereby reducing variance of the pooled estimator. ${ }^{9}$ This model uses a synthetic bias variance to adjust inverse variance weights and achieves an estimator variance that is smaller than that of the random effects estimator. This synthetic bias variance is computed through the quality assessment and, regardless of how subjective the assessment is, so long as it has some information value, the estimator variance decreases. Furthermore, this model also overcomes the coverage problems seen with the random effects estimator for which corrections have been attempted. ${ }^{14} \mathrm{We}$, nevertheless, report conventional results (random effects and fixed effects models, see supplementary material) for comparison. All analyses utilized MetaXL version 2.0 (Epigear International Pty Ltd, Brisbane, Australia; www.epigear.com). We preferred MetaXL in this analysis, since it has both an improved methodology of meta-analysis of multi-category prevalence ${ }^{7}$ as well as the ability to execute bias adjusted analyses. By bias adjustment, we mean that weighting done under this model allows the results of the "big" studies (with less bias) to make a greater contribution to the pooled effect, thus decreasing overall bias of the estimator. In computing the pooled proportions using MetaXL, the double arcsine square root transformation was used to stabilize variance of the proportion and results back transformed for reporting 95\% confidence intervals around pooled estimates were computed as previously reported. ${ }^{7,5}$

We determined whether heterogeneity (clinical, statistical, or methodological) existed among studies that we included in the meta-analysis by drawing up forest plots (figures 2 and 3) to graphically present individual and pooled estimates as well as using the heterogeneity statistics; the Cochran's Q and $\mathrm{I}^{2}$ statistic, which examine the percentage variation across studies due to heterogeneity. ${ }^{15}$ A sensitivity analysis by altering various study selection criteria including study size, year of study, monitoring of therapy, and country of origin
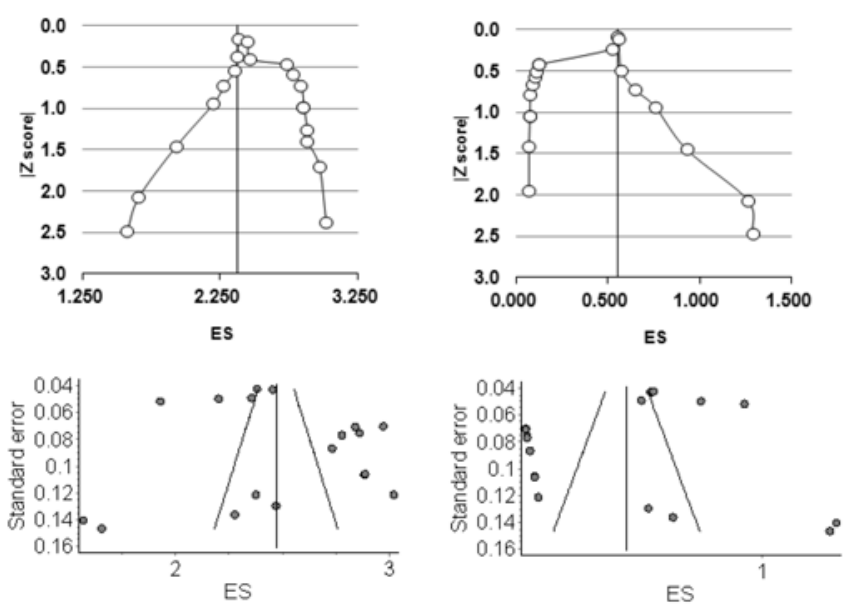

Figure 4. Doi plots (top) and funnel plots (bottom) for D/D regimens among success (left) and defaulter (right) proportions on the double arcsine square root scale (ES).
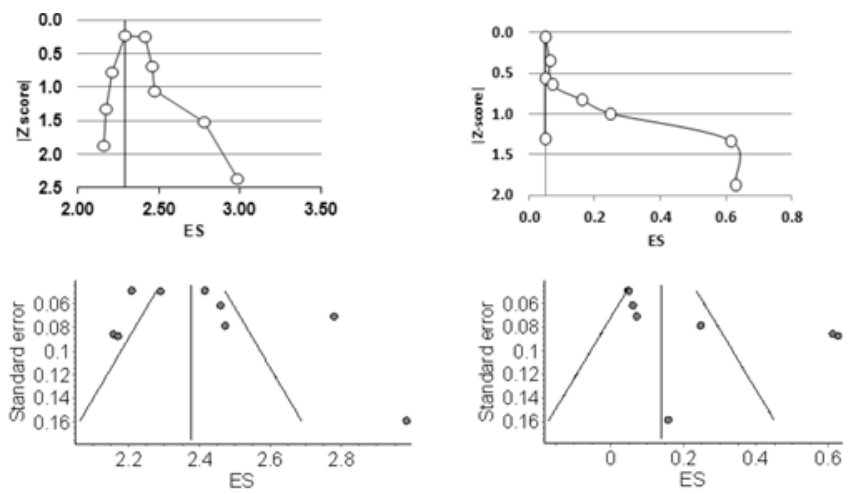

Figure 5. Doi plots (top) and funnel plots (bottom) for the $\mathrm{I} / \mathrm{I}$ regimens among success (left) and default (right) proportions on the double arcsine square root scale (ES).

were computed. We also compared results across different meta-analysis models for outcome comparison. In addition, we looked for publication bias through Doi and funnel plots $^{15-17}$ (figures 4 and 5).

\section{Results}

\section{Description of the Studies Included}

We identified 3,179 studies from the three electronic databases, of which 806 were duplicates and 2,128 were excluded by title (figure 1). We, therefore, retained 245 titles for abstract review, from which 127 abstracts were excluded, leaving 118 abstracts for review. Upon review of these abstracts as full text, 98 were excluded, thereby leaving 20 studies to be included in the meta-analysis. An additional 7 studies were identified through a related citation search of already identified original articles, thereby obtaining a total of 27 studies that were included in this meta-analysis. 
Table 1. Tuberculosis treatment outcomes (37 datasets from 18 studies)

\begin{tabular}{|c|c|c|c|c|c|}
\hline Regimen & Success & Failed & Relapsed & Defaulted & Total \\
\hline \multicolumn{6}{|l|}{ Rifampicin throughout } \\
\hline $\begin{array}{l}\text { ( } \mathrm{n}=9 \text { datasets) } \\
\text { Daily* }\end{array}$ & $0.88(0.81-0.92)$ & $0.05(0.02-0.09)$ & $0.07(0.03-0.11)$ & $0.00(0.00-0.02)$ & 1 \\
\hline (n=19 datasets) & $0.90(0.84-0.95)$ & $0.04(0.01-0.08)$ & $0.01(0.00-0.03)$ & $0.05(0.01-0.09)$ & 1 \\
\hline Overall & $0.91(0.84-0.95)$ & $0.03(0.01-0.08)$ & $0.01(0.00-0.03)$ & $0.04(0.01-0.09)$ & 1 \\
\hline \multicolumn{6}{|l|}{ Rifampicin only in IP } \\
\hline Daily* ( $n=9$ datasets) & $0.75(0.57-0.91)$ & $0.05(0.00-0.15)$ & $0.02(0.00-0.09)$ & $0.15(0.02-0.30)$ & 1 \\
\hline
\end{tabular}

We obtained 48 data sets from all included studies with 10,624 participants that were enrolled across these studies. Out of the 10,624 participants, 7,611 were on completely daily treatment (28 datasets) and 3,013 on completely intermittent therapy ( 9 datasets). Of the 10,624 participants, 8,336 were on regimens that contained rifampicin in both IP and CP (28 datasets), while 2,228 were on regimens that had rifampicin in IP only ( 9 datasets). All included studies involved HIV sero-negative adults (except 4 studies; first with 6 , second with 115 , third with 77 , and the fourth with 32 HIV sero-positive participants ${ }^{18-21}$ ) with smear positive pulmonary TB (except in one study, 67 out of 198 patients were smear negative ${ }^{22}$ ). Moreover, in one study, a third of the 1,240 patients included were previously treated. ${ }^{23}$ In all these scenarios, ineligible patients could not be excluded by both regimen type and treatment outcome. Again, instead of rifampicin (R), rifabutin was used in two of the studies included with a total of 491 participants. ${ }^{24,25}$ Treatment doses were fully supervised in eleven studies, ${ }^{19-21,23,26-32}$ supervised as well as self-administered in nine studies, ${ }^{22,25,33-38}$ and only self-administered in two, ${ }^{39,40}$ while treatment modality was unspecified in five studies. ${ }^{18,24,41-43}$

\section{Pooled Results}

Primary outcome - same intensity of dosing throughout Intermittent regimens:

Rifampicin was administered intermittently (I/I) in both phases (twice to thrice weekly) in nine datasets; all of these datasets had a CP of 4 months. ${ }^{23,24,26,28,30,44}$ The overall treatment success with this intermittent regimen was $88 \%$ (95\% CI, 81-92), failure and relapse rates were 5\% (95\% CI, $2-9)$ versus $7 \%(95 \% \mathrm{CI}, 3-11)$, and default rate was $0 \%(95 \%$ CI, 0-2) (table 1).

Daily regimens:

Rifampicin was administered daily (D/D) in both phases in 19 datasets. $18,19,21,22,25-27,29,36,39-41,43$ The overall treatment success was $90 \%(95 \% \mathrm{CI}, 84-95)$ with failure and relapse rates of $4 \%$ (95\% CI, $1-8)$ and $1 \%(95 \% \mathrm{CI}, 0-3)$, but default rates of $5 \%$ (95\% CI, 1-9).
Secondary outcomes

Mixed regimens:

There were eight datasets ${ }^{20,31,33,34,45}$ with daily/intermittent $(\mathrm{D} / \mathrm{I})$ therapy that used rifampicin throughout, and they achieved $91 \%$ (95\% CI, 86-96) success, 3\% (95\% CI, 1-7) failure, $4 \%(95 \% \mathrm{CI}, 1-8)$ relapse, and only $1 \%(95 \% \mathrm{CI}, 0-3)$ default.

\section{Rifampicin Only in IP}

There were nine datasets reporting results of $\mathrm{D} / \mathrm{D}$ regimens. $19,35,38,42,44$ These regimens had an overall treatment success of $75 \%$ (95\% CI, 57-91). The failure and relapse rates were $5 \%(95 \% \mathrm{CI}, 0-15)$ and $2 \%(95 \% \mathrm{CI}, 0-9)$, but the default rates were $15 \%(95 \% \mathrm{CI}, 2-30)$.

There were two studies' of I/D administration of 6 months. ${ }^{19,37}$ The overall treatment success among these regimens having no rifampicin in the CP was $81 \%(95 \% \mathrm{CI}, 31-100)$, with failure and relapse rates of $8 \%(95 \% \mathrm{CI}, 0-47)$ versus $5 \%$ $(95 \% \mathrm{CI}, 0-42)$ and default rate of $3 \%(95 \% \mathrm{CI}, 0-36)$.

There was one study of a D/I therapy that did not use rifampicin in the $\mathrm{CP}$ and of 6 months duration. ${ }^{45}$ It reported a treatment success of $74 \%$ (95\% CI, 64-84), with failure and relapse rates of $26 \%$ (95\% CI, $16-36)$ versus $0 \%(95 \% \mathrm{CI}$, $0-2)$ and default rate of $0 \%(95 \% \mathrm{CI}, 0-2)$ (table 1$)$.

\section{Sensitivity Analysis}

Sensitivity analysis was done for the D/D studies by altering selection criteria such as regimen type, treatment duration, dosing frequency, treatment outcome and comparing treatment outcome results across different meta-analysis models. More still, comparisons were made by examining treatment outcomes in relation to study size, year of publication, country where study was conducted as well as whether therapy was monitored or not. No significant differences were observed across treatment outcomes under both quality effect and fixed effect (IVhet) meta-analysis models. For instance, under a quality effects model, the $\mathrm{D} / \mathrm{D}$ group with rifampicin administered throughout, treatment success among bigger and smaller studies were $90 \%$ (95\% CI, 82-96) versus $91 \%$ (95\% CI, 81-99). Again, in the D/D group with rifampicin administered throughout, the treatment success was comparable among studies where therapy were fully 
supervised (90\%) (95\% CI, 74-1.00) and not fully/ unsupervised (90\%) (95\% CI, 83-95) (table 2).

\section{Publication Bias}

We evaluated publication bias through visual inspection of funnel plots based on standard error (figures 4 and 5). We observed that they were not interpretable, which is in keeping with the observation that visual inspection of funnel plots can misrepresent bias and be misleading as well. ${ }^{15,17,46} \mathrm{We}$ further examined publication bias using the Doi plot. The Doi plots for treatment success for $\mathrm{D} / \mathrm{D}$ regimens were more or less symmetrical suggesting no gross bias (figure 4). For I/I regimens, there was gross asymmetry for both success and default proportions with possible heterogeneity across the studies favoring more success but more default as well, and thus, low default proportions with these regimens are unlikely to have been influenced by under-reporting (figures 4 and 5).

\section{Discussion}

In this study of 27 studies involving EHRZ in the initial phase of TB treatment, administration of therapy intermittently (I/I) twice or three times a week rather than daily (D/D) was associated with similar treatment outcomes of success and failure (table 1, and figures 2 and 3). The most important finding of this meta-analysis, however, was that there was a trade-off between default and relapse rates between $\mathrm{D} / \mathrm{D}$ and I/I regimens (table 1). Default rates were low with the I/I regimens, and these finding concur with that reported by individual reports of intermittent WHO category 1 TB treatment regimen involving EHRZ. ${ }^{44,47,48}$ Thus, the important issue in fully intermittent regimens is those of better treatment compliance and adherence rather than of regimen efficacy. Indeed, intermittent regimens have been found to offer practical solutions to high pill burdens, inconvenience, and intractable drug adverse reactions associated with daily TB therapies. ${ }^{1,49}$

The trade-off, however, is with increase in relapse with I/I that is matched by the increase in default with $\mathrm{D} / \mathrm{D}$. The $\mathrm{D} / \mathrm{I}$ regimen had a slightly lower default but relapse was still higher. This finding is supported by a review ${ }^{6}$ that examined intermittent therapy of thrice weekly versus daily therapy in a single randomized trial ${ }^{26}$ where intermittent therapy was administered and recurrence was increased 4 fold with intermittent therapy (non-significant) compared to the daily group, but no conclusions were drawn. These observed differences in treatment relapse versus default rates were not reported by Menzies et $\mathrm{al}^{3}$ because they used pooled cumulative incidences, adjusted incidence rate ratios, and risk differences only on outcomes of failure, relapse, and acquired drug resistance and did not separate out rifampicin duration and intermittency of therapy. In our case, we used proportions of successfully treated, failure, relapse, and default as separate categories and pooled them simultaneously. Analyses were also done separately for regimens with rifampicin in all phases versus rifampicin in IP only. We believe that these results point towards the fact that I/I regimens possibly require a longer duration than 6 months to prevent relapses, since a systematic review by Chang et $\mathrm{al}^{50}$ suggests that extending treatment of 6-month regimens may reduce relapse of TB. The intermediate option, the D/I regimens, do not solve the relapse issue seen with $\mathrm{I} / \mathrm{I}$ regimens.

Twelve studies had no rifampicin in the $\mathrm{CP}$ and included two studies ${ }^{19,37}$ involving I/D, nine studies ${ }^{19,35,38,42,44}$ using $\mathrm{D} / \mathrm{D}$, and one study using $\mathrm{D} / \mathrm{I} .{ }^{45}$ These regimens with shorter durations of rifampicin usage were found by Menzies and colleagues ${ }^{3}$ to have high unfavorable treatment outcomes. Menzies et al report a pooled event rate of 1.8 (CI, 0.2-3.3) versus 0.4 (CI, 0.1-0.7) for failure, 16 (CI, 11.1-20.9) versus 3.8 (CI, 2.9-4.7) for relapse, and $0.8(\mathrm{CI}, 0-1.6)$ versus $0.4(\mathrm{CI}, 0.1-0.7)$ for acquired drug resistance, respectively when comparing 2 months with 6 months of rifampicin. ${ }^{3}$ Our data, however, suggest that if we compare $\mathrm{D} / \mathrm{D}$ to $\mathrm{D} / \mathrm{D}$ regimens with long and short rifampicin treatment, what differs is default rates $-5 \%(\mathrm{CI}, 1-10)$ versus $15 \%(\mathrm{CI}, 2-30)$. Thus, these regimens

\begin{tabular}{|c|c|c|c|c|c|c|}
\hline Criteria & Cut off & Datasets & Success & Failed & Relapsed & Defaulted \\
\hline \multirow[t]{2}{*}{ Study size } & Small $<166$ & 9 & $\begin{array}{l}0.91 \\
(0.81-0.99)\end{array}$ & $\begin{array}{l}0.03 \\
(0.00-0.10)\end{array}$ & $\begin{array}{l}0.02 \\
(0.00-0.08)\end{array}$ & $\begin{array}{l}0.03 \\
(0.00-0.10)\end{array}$ \\
\hline & Big $\geq 166$ & 10 & $\begin{array}{l}0.90 \\
(0.82-0.96)\end{array}$ & $\begin{array}{l}0.04 \\
(0.00-0.08)\end{array}$ & $\begin{array}{l}0.01 \\
(0.00-0.03)\end{array}$ & $\begin{array}{l}0.05 \\
(0.01-0.11)\end{array}$ \\
\hline \multirow[t]{2}{*}{$\begin{array}{l}\text { Year of } \\
\text { publication }\end{array}$} & Before 1999 & 8 & $\begin{array}{l}0.98 \\
(0.97-0.99)\end{array}$ & $\begin{array}{l}0.01 \\
(0.00-0.02)\end{array}$ & $\begin{array}{l}0.01 \\
(0.01-0.02)\end{array}$ & $\begin{array}{l}0.00 \\
(0.00-0.00)\end{array}$ \\
\hline & 1999 and after & 11 & $\begin{array}{l}0.84 \\
(0.76-0.91)\end{array}$ & $\begin{array}{l}0.05 \\
(0.01-0.10)\end{array}$ & $\begin{array}{l}0.01 \\
(0.00-0.03)\end{array}$ & $\begin{array}{l}0.09 \\
(0.04-0.15)\end{array}$ \\
\hline \multirow[t]{2}{*}{ Country } & $\begin{array}{l}\text { African or } \\
\text { African with } \\
\text { other settings }\end{array}$ & 4 & $\begin{array}{l}0.92 \\
(0.84-0.98)\end{array}$ & $\begin{array}{l}0.02 \\
(0.00-0.07)\end{array}$ & $\begin{array}{l}0.01 \\
(0.00-0.05)\end{array}$ & $\begin{array}{l}0.04 \\
(0.00-0.10)\end{array}$ \\
\hline & $\begin{array}{l}\text { purely non- } \\
\text { African }\end{array}$ & 15 & $\begin{array}{l}0.89 \\
(0.80-0.97)\end{array}$ & $\begin{array}{l}0.04 \\
(0.00-0.10)\end{array}$ & $\begin{array}{l}0.01 \\
(0.00-0.04)\end{array}$ & $\begin{array}{l}0.05 \\
(0.00-0.12)\end{array}$ \\
\hline \multirow[t]{2}{*}{$\begin{array}{l}\text { Monitored } \\
\text { therapy }\end{array}$} & Fully & 6 & $\begin{array}{l}0.90 \\
(0.74-1.00)\end{array}$ & $\begin{array}{l}0.04 \\
(0.00-0.15)\end{array}$ & $\begin{array}{l}0.02 \\
(0.00-0.10)\end{array}$ & $\begin{array}{l}0.04 \\
(0.00-0.16)\end{array}$ \\
\hline & $\begin{array}{l}\text { Partly/ not at } \\
\text { all/unspecified }\end{array}$ & 13 & $\begin{array}{l}0.90 \\
(0.83-0.95)\end{array}$ & $\begin{array}{l}0.04 \\
(0.00-0.08)\end{array}$ & $\begin{array}{l}0.01 \\
(0.00-0.03)\end{array}$ & $\begin{array}{l}0.05 \\
(0.01-0.10)\end{array}$ \\
\hline
\end{tabular}


are unsuccessful, because subjects default rather than relapse. Menzies et $\mathrm{al}^{51}$ were not able to demonstrate this, because they did not separate out duration of rifampicin from intensity (frequency) of therapy. These observed differences for short duration rifampicin based regimens which could therefore possibly be explained by increased default possibly due to ethambutol related toxicity.

There were some studies that appeared to be outliers in the forest plot (figure 2 and 3), but none of the studies gave any details. McGregor et $\mathrm{al}^{24}$ report that 24 defaulted, but no reasons were given. $\mathrm{Su}$ et $\mathrm{al}^{39}$ reported that only 51 out of 105 patients enrolled into the study completed the full course. Analysis of the study report indicates a possible poor patient management protocol that led to a high attrition rate, and 33 defaulted. In addition to defaulters, $51.4 \%$ of the study participants never completed. Similarly, Nunn et $\mathrm{al}^{19}$ appeared as an outlier, because 237 patients defaulted, but again no reason was given, except that they mention default rates were similar across all three regimens they compared.

This meta-analysis had a number of limitations. Most studies that reported drug resistance did not uniformly provide elaborate information among their findings. The few that attempted to do this did not provide information in a standard manner to facilitate useful analysis that could yield generalizable results. Therefore, this study did not look at the effect of primary drug resistance on the outcomes; neither did it look at acquired drug resistance. More still, although three trials incorporated in this meta-analysis included a few HIV sero-positive TB patients, this study was unable to determine their impact on the overall results. However, in a separate study involving HIV infected TB patients, intermittent TB therapy with rifampicin based regimens alone on a twice weekly dosing schedule in the initial phase but not in the continuation phase, was associated with high risk of relapses and an increased risk of acquired rifampicin resistance. ${ }^{52}$ Such studies were, however, given a lower quality score, which mitigates this to some extent. Another major limitation was the fact that there were fewer studies done involving completely intermittent therapy, thereby limiting the number of studies available for this analysis. However, follow up was satisfactory in all studies, except in three where the follow-up period was less than one year, but this finding is not expected to affect study results, since the majority of studies had more than one year of follow-up period. Again, these studies were given a lower quality score.

\section{Conclusion}

In conclusion, poor treatment compliance and adherence due to longer duration of therapy is linked to poor outcomes, ${ }^{53,54}$ and thus, to ensure improved treatment efficacy and adherence as well as compliance, we believe that there is a need to switch to treatment regimens containing rifampicin in both phases that are offered I/I while ensuring directly observed therapy among HIV sero-negative TB patients, since they are associated with similar treatment success and failure and low default rates. However, relapse rates are higher, and it is possible that this could be mitigated by a longer duration of more than 6 months of therapy, but this needs to be further investigated urgently by future studies.

\section{References}

1. Gebremariam MK, Bjune GA, Frich JC. Barriers and facilitators of adherence to TB treatment in patients on concomitant TB and HIV treatment: a qualitative study. BMC Public Health 2010;10:651.

2. Mandal PK, Mandal A, Bhattacharyya SK. Comparing the Daily Versus the Intermittent Regimens of the Anti-Tubercular Chemotherapy in the Initial Intensive Phase in Non-HIV, Sputum Positive, Pulmonary Tuberculosis Patients. J Clin Diagn Res 2013;7:292-295.

3. Menzies D, Benedetti A, Paydar A, Martin I, Royce S, Pai M, Vernon A, Lienhardt C, Burman W. Effect of duration and intermittency of rifampin on tuberculosis treatment outcomes: a systematic review and meta-analysis. PLoS Med 2009;6:e1000146.

4. WHO. Treatment of tuberculosis: guidelines: World Health Organization, 2010.

5. WHO. WHO, Global Tuberculosis Report. Printed in France, 2012.

6. Mwandumba HC, Squire SB. Fully intermittent dosing with drugs for treating tuberculosis in adults. The Cochrane Database Syst Rev 2001;(4):Cd000970.

7. Barendregt JJ, Doi SA, Lee YY, Norman RE, Vos T. Metaanalysis of prevalence. J Epidemiol Community Health 2013;67:974-978.

8. Hoy D, Brooks P, Woolf A, Blyth F, March L, Bain C, Baker P, Smith E, Buchbinder R. Assessing risk of bias in prevalence studies: modification of an existing tool and evidence of interrater agreement. J Clin Epidemiol 2012;65:934-939.

9. Doi SA, Barendregt JJ, Williams GM, Khan S, Thalib L. Simulation Comparison of the Quality Effects and Random Effects Methods of Meta-analysis. Epidemiology 2015;26:e42-e44.

10. WHO. WHO, Table A2.1. Definitions of tuberculosis cases and treatment outcomes. 2012.

11. WHO. Definitions and reporting framework for tuberculosis-2013 revision. World Health Organization Document 2013: 1-40.

12. WHO. WHO, Guidelines for the programmatic management of drug-resistant tuberculosis, Emergency update 2008. 20 Avenue Appia, 1211 Geneva 27, Switzerland: WHO Press, World Health Organization, 2008:1-272.

13. Doi SA, Thalib L. A quality-effects model for meta-analysis. Epidemiology 2008;19:94-100.

14. Noma H. Confidence intervals for a random-effects metaanalysis based on Bartlett-type corrections. Stat Med 2011;30:3304-3312.

15. Doi SA, Williams GM. Methods of clinical epidemiology. New York: Springer Berlin Heidelberg, 2013.

16. Field AP, Gillett R. How to do a meta-analysis. Br J Math Stat Psychol 2010;63:665-694.

17. Sterne JA1, Sutton AJ, Ioannidis JP, Terrin N, Jones DR, Lau J, Carpenter J, Rücker G, Harbord RM, Schmid CH, Tetzlaff J, Deeks JJ, Peters J, Macaskill P, Schwarzer G, Duval S, Altman DG, Moher D, Higgins JP. Recommendations for examining and interpreting funnel plot asymmetry in metaanalyses of randomised controlled trials. BMJ 2011;343:d4002.

18. Bartacek A, Schutt D, Panosch B, Borek M; Rimstar 4-FDC Study Group. Comparison of a four-drug fixed-dose combination regimen with a single tablet regimen in smearpositive pulmonary tuberculosis. Int J Tuberc Lung Dis 2009;13:760-766.

19. Nunn AJ, Jindani A, Enarson DA. Results at 30 months of a 
randomised trial of two 8-month regimens for the treatment of tuberculosis. Int J Tuberc Lung Dis 2011;15:741-745.

20. Lienhardt C, Cook SV, Burgos M, Yorke-Edwards V, Rigouts L, Anyo G, Kim SJ, Jindani A, Enarson DA, Nunn AJ; Study C Trial Group. Efficacy and safety of a 4-drug fixed-dose combination regimen compared with separate drugs for treatment of pulmonary tuberculosis: the Study $\mathrm{C}$ randomized controlled trial. JAMA 2011;305:1415-1423.

21. Kennedy N, Berger L, Curram J, Fox R, Gutmann J, Kisyombe GM, Ngowi FI, Ramsay AR, Saruni AO, Sam N, Tillotson G, Uiso LO, Yates M, Gillespie SH. Randomized controlled trial of a drug regimen that includes ciprofloxacin for the treatment of pulmonary tuberculosis. Clin Infect Dis 1996;22:827-833.

22. Johnson JL, Hadad DJ, Dietze R, Maciel EL, Sewali B, Gitta P, Okwera A, Mugerwa RD, Alcaneses MR, Quelapio MI, Tupasi TE, Horter L, Debanne SM, Eisenach KD, Boom WH. Shortening treatment in adults with noncavitary tuberculosis and 2-month culture conversion. Am J Respir Crit Care Med. 2009;180:558-563.

23. Santha T, Rehman F, Mitchison DA, Sarma GR, Reetha AM, Prabhaker R; ulosis Research Centre, Indian Council of Medical Research. Split-drug regimens for the treatment of patients with sputum smear-positive pulmonary tuberculosis-a unique approach. Trom Med Int Health 2004;9:551-558.

24. McGregor MM, Olliaro P, Wolmarans L, Mabuza B, Bredell M, Felten MK, Fourie PB. Efficacy and safety of rifabutin in the treatment of patients with newly diagnosed pulmonary tuberculosis. Am J Respir Crit Care Med 1996;154:14621467.

25. Gonzalez-Montaner LJ, Natal S, Yongchaiyud P, Olliaro P. Rifabutin for the treatment of newly-diagnosed pulmonary tuberculosis: A multinational, randomized, comparative study versus Rifampicin. Rifabutin Study Group. Tuber Lung Dis 1994;75:341-347.

26. Controlled trial of four thrice-weekly regimens and a daily regimen all given for 6 months for pulmonary tuberculosis. Lancet 1981;1:171-174.

27. Sharifi-Mood B, Metanat M, Alavi-Naini R, Kouhpayeh HR, Salehi M, Naderi M, Hashemi-Shahri SM, Naser-Poor T. The comparison of six-month and four-month regimens of chemotherapy in the treatment of smear positive pulmonary tuberculosis. J Med Sci 2006;6:108-111.

28. Macnab MF, Bohmer PD, Seager JR. Evaluation of the 3-drug combination, Rifater, versus 4-drug therapy in the ambulatory treatment of tuberculosis in Cape Town. S Afr Med J1994;84:325-328.

29. Chuchottaworn C, Saipan B, Kittisup C, Cheewakul K. Adverse drug reactions and outcome of short course antituberculosis drugs between single daily dose and split drug dose (BID) in pulmonary tuberculosis. J Med Assoc Thai 2012;95:S1-S5.

30. Jawahar MS, Banurekha VV, Paramasivan CN, Rahman F, Ramachandran R, Venkatesan P, Balasubramanian R, Selvakumar N, Ponnuraja C, Iliayas AS, Gangadevi NP, Raman B, Baskaran D, Kumar SR, Kumar MM, Mohan V, Ganapathy S, Kumar V, Shanmugam G, Charles N, Sakthivel MR, Jagannath K, Chandrasekar C, Parthasarathy RT, Narayanan PR. Randomized clinical trial of thrice-weekly 4-month moxifloxacin or gatifloxacin containing regimens in the treatment of new sputum positive pulmonary tuberculosis patients. PloS One 2013;8:e67030.

31. Gravendeel JM, Asapa AS, Becx-Bleumink M, Vrakking HA. Preliminary results of an operational field study to compare side-effects, complaints and treatment results of a single-drug short-course regimen with a four-drug fixed-dose combination (4FDC) regimen in South Sulawesi, Republic of Indonesia. Tuberculosis (Edin) 2003;83:183-186.

32. Felten MK. Importance of rifampicin in combined daily/ intermittent chemotherapy for tuberculosis. S Afr Med J 1989;75:524-526.

33. Suryanto AA, van den Broek J, Hatta M, de Soldenhoff R, van der Werf MJ. Is there an increased risk of TB relapse in patients treated with fixed-dose combination drugs in Indonesia? Int J Tuberc Lung Dis 2008;12:174-179.

34. Perriens JH, St Louis ME, Mukadi YB, Brown C, Prignot J, Pouthier F, Portaels F, Willame JC, Mandala JK, Kaboto M, et al. Pulmonary tuberculosis in HIV-infected patients in Zaire. A controlled trial of treatment for either 6 or 12 months. N Eng J Med 1995;332:779-784.

35. Walley JD, Khan MA, Newell JN, Khan MH. Effectiveness of the direct observation component of DOTS for tuberculosis: a randomised controlled trial in Pakistan. Lancet 2001;357:664-669.

36. Kamolratanakul P, Sawert H, Lertmaharit S, Kasetjaroen Y, Akksilp S, Tulaporn C, Punnachest K, Na-Songkhla S, Payanandana V. Randomized controlled trial of directly observed treatment (DOT) for patients with pulmonary tuberculosis in Thailand. Trans R Soc Trop Med Hyg 1999;93:552-557.

37. Evaluation of a non-rifampicin continuation phase (6HE) following thrice-weekly intensive phase for the treatment of new sputum positive pulmonary tuberculosis. Indian J Tuberc 2007;54:84-90.

38. Faisal AR, Qazi RA, Iqbal M, Waseemuddin J, Rehmani F, Bashir T. Effectiveness of directly observed treatment strategy (dots) as compared to self-administered therapy in tuberculosis. Ann Pak Inst Med Sci 2005;1:79-83.

39. Su WJ, Perng RP. Fixed-dose combination chemotherapy (Rifater/Rifinah) for active pulmonary tuberculosis in Taiwan: a two-year follow-up. Int J Tuberc Lung Dis 2002;6:1029-1032.

40. A controlled trial of 6 months' chemotherapy in pulmonary tuberculosis. Final report: results during the 36 months after the end of chemotherapy and beyond. British Thoracic Society. Br J Dis Chest 1984;78:330-336.

41. Baba H, Shinkai A, Izuchi R, Azuma Y. [Long-term results of short-course chemotherapy of pulmonary tuberculosis (second study--A). Results up to 6 years after the end of treatment with 4-6 month chemotherapy of pulmonary tuberculosis.] Kekkaku 1987;62:329-339 [Article in Japanese.]

42. Punnotok J, Pumprueg U, Chakorn T. A comparison of two short course tuberculosis chemotherapy regimens, both using Rifater during an intensive phase, with a 3 year follow-up. J Med Assoc Thai 1995; 78:298-304.

43. Howell F, O'Laoide R, Kelly P, Power J, Clancy L. Short course chemotherapy for pulmonary tuberculosis. A randomised controlled trial of a six month versus a nine month oral regimen. Ir Med J 1989;82:11-13.

44. A controlled clinical trial of oral short-course regimens in the treatment of sputum-positive pulmonary tuberculosis. Tuberculosis Research Centre. Int J Tuberc Lung Dis 1997;1:509-517.

45. Felten MK. Importance of rifampicin in combined daily/ intermittent chemotherapy for tuberculosis. S Afr Med J 1989;75:524-526.

46. Hunter JP, Saratzis A, Sutton AJ, Boucher RH, Sayers RD, Bown MJ. In meta-analyses of proportion studies, funnel plots were found to be an inaccurate method of assessing publication bias. J Clin Epidemiol 2014;67:897-903.

47. Banu Rekha VV, Rajaram K, Kripasankar AS, Parthasarathy R, Umapathy KC, Sheikh I, Selvakumar N, Victor M, Niruparani C, Sridhar R, Jawahar MS. Efficacy of the 6-month thrice-weekly regimen in the treatment of new sputum smear-positive pulmonary tuberculosis under clinical trial conditions. Natl Med J India 2012;25:196-200.

48. Chaisson RE, Clermont HC, Holt EA, Cantave M, Johnson MP, 
Atkinson J, Davis H, Boulos R, Quinn TC, Halsey NA. Sixmonth supervised intermittent tuberculosis therapy in Haitian patients with and without HIV infection. Am J Respir Crit Care Med 1996;154:1034-1038.

49. Mandal PK, Mandal A, Bhattacharyya SK. Comparing the Daily Versus the Intermittent Regimens of the AntiTubercular Chemotherapy in the Initial Intensive Phase in Non-HIV, Sputum Positive, Pulmonary Tuberculosis Patients. J Clin Diagn Res 2013;7:292-295.

50. Chang KC, Leung CC, Yew WW, Chan SL, Tam CM. Dosing schedules of 6-month regimens and relapse for pulmonary tuberculosis. Am J Respir Crit Care Med 2006;174:11531158.

51. Pyle MM. Ethambutol in the retreatment and primary treatment of tuberculosis: a four-year clinical investigation. Ann N Y Acad Sci 1966; 135:835-845.

52. Li J, Munsiff SS, Driver CR, Sackoff J. Relapse and acquired rifampin resistance in hiv-infected patients with tuberculosis treated with rifampin- or rifabutin-based regimens in New York City, 1997-2000. Clin Infect Dis 2005;41:83-91.

53. Munro SA, Lewin SA, Smith HJ, Engel ME, Fretheim A, Volmink J. Patient adherence to tuberculosis treatment: a systematic review of qualitative research. PLoS Med 2007;4:e238.

54. Chirwa T, Nyasulu P, Chirwa E, Ketlogetswe A, Bello G, Dambe I, Ndalama D, Joshua M. Levels of tuberculosis treatment adherence among sputum smear positive pulmonary tuberculosis patients attending care at Zomba Central hospital, southern Malawi, 2007-2008. PloS One 2013;8:e63050.

\section{Author Affiliations}

Samuel Kasozi, MBchB, MIPH, ${ }^{*},+$ Justin Clark, BA, Lib Tech ; Suhail A. R. Doi, MBBS, FRCP, MClinEpid, PhD

*National Tuberculosis and Leprosy Control Program, Ministry of Health, Wandegeya, Uganda

School of Public Health, Makerere University, Uganda

* School of Population Health, University of Queensland, Brisbane, Australia

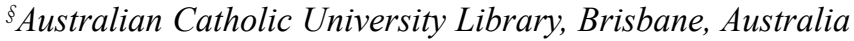

Research School of Population Health, Australian National University, Canberra, Australia

\section{Supplementary Material}

Details of the Search String

\section{PubMed search}

"Tuberculosis"[Mesh] OR Tuberculosis OR Tuberculoses OR "Kochs Disease" OR "Koch's Disease" OR "Koch Disease" AND

"Therapeutics"[Mesh] OR Therapeutics OR Therapeutic OR Treatment OR Treatments OR Therapy OR Therapies

AND

"Treatment Outcome"[Mesh] OR Effectiveness OR Efficacy OR Failure OR Relapse OR "Drug resistance"

\section{Cochrane search}

\#1: MeSH descriptor: [Tuberculosis] explode all trees

\#2: Tuberculosis or Tuberculoses or "Kochs Disease" or "Koch's Disease" or "Koch Disease"

\#3: MeSH descriptor: [Therapeutics] explode all trees

\#4: Therapeutics or Therapeutic or Treatment or Treatments or Therapy or Therapies

\#5: MeSH descriptor: [Treatment Outcome] explode all trees

\#6:Effectiveness or Efficacy or Failure or Relapse or "Drug resistance"

\#7: \#1 or \#2

$\# 8$ : $\# 3$ or $\# 4$

$\# 9$ : $\# 5$ or $\# 6$

$\# 10$ : \#7 and \#8 and \#9

\section{Embase search}

'tuberculosis'/exp OR tuberculosis OR tuberculoses OR 'kochs disease' OR 'koch disease'

AND

('therapeutics'/exp OR therapeutics OR therapeutic OR treatment OR treatments OR 'therapy'/exp OR therapy OR therapies)

AND

('treatment outcome'/exp OR effectiveness OR efficacy OR failure OR 'relapse'/exp OR relapse OR 'drug resistance'/exp OR 'drug resistance')

AND

([controlled clinical trial]/lim OR [randomized controlled trial]/lim) AND

[english]/lim

AND

[embase]/lim 
Table S1. TB treatment outcomes - IVhet model (fixed effects with over dispersion correction).

\begin{tabular}{|c|c|c|c|c|c|}
\hline Regimen & Success & Failed & Relapsed & Defaulted & Total \\
\hline \multicolumn{6}{|c|}{ Rifampicin throughout } \\
\hline Intermittent $(n=9)$ & $0.87(0.80-0.91)$ & $0.06(0.02-0.10)$ & $0.07(0.03-0.11)$ & $0.00(0.00-0.02)$ & 1 \\
\hline Daily $(n=19)$ & 0.89 (0.82-0.95) & $0.04(0.00-0.08)$ & 0.01 (0.00-0.03) & $0.05(0.01-0.10)$ & 1 \\
\hline Overall & $0.90(0.82-0.95)$ & $0.04(0.00-0.08)$ & $0.01(0.00-0.03)$ & $0.05(0.01-0.10)$ & 1 \\
\hline \multicolumn{6}{|c|}{ Rifampicin only in IP } \\
\hline Daily $(n=9)$ & $0.75(0.55-0.92)$ & $0.05(0.00-0.17)$ & $0.02(0.00-0.11)$ & $0.14(0.01-0.30)$ & 1 \\
\hline
\end{tabular}

Table S2. TB treatment outcomes - random effects model (underestimates the statistical error)

\begin{tabular}{|c|c|c|c|c|c|}
\hline Regimen & Success & Failed & Relapsed & Defaulted & Total \\
\hline \multicolumn{6}{|c|}{ Rifampicin throughout } \\
\hline Intermittent $(n=9)$ & $0.89(0.83-0.92)$ & $0.04(0.02-0.08)$ & $0.06(0.03-0.09)$ & $0.01(0.00-0.03)$ & 1 \\
\hline Daily $(n=19)$ & $0.91(0.85-0.95)$ & $0.03(0.01-0.06)$ & $0.01(0.00-0.03)$ & $0.04(0.01-0.08)$ & 1 \\
\hline Overall & $0.92(0.85-0.95)$ & $0.03(0.01-0.06)$ & $0.01(0.00-0.03)$ & $0.04(0.01-0.08)$ & 1 \\
\hline \multicolumn{6}{|c|}{ Rifampicin only in IP } \\
\hline Daily $(n=9)$ & $0.77(0.61-0.90)$ & $0.04(0.00-0.13)$ & $0.01(0.00-0.07)$ & $0.14(0.04-0.29)$ & 1 \\
\hline
\end{tabular}




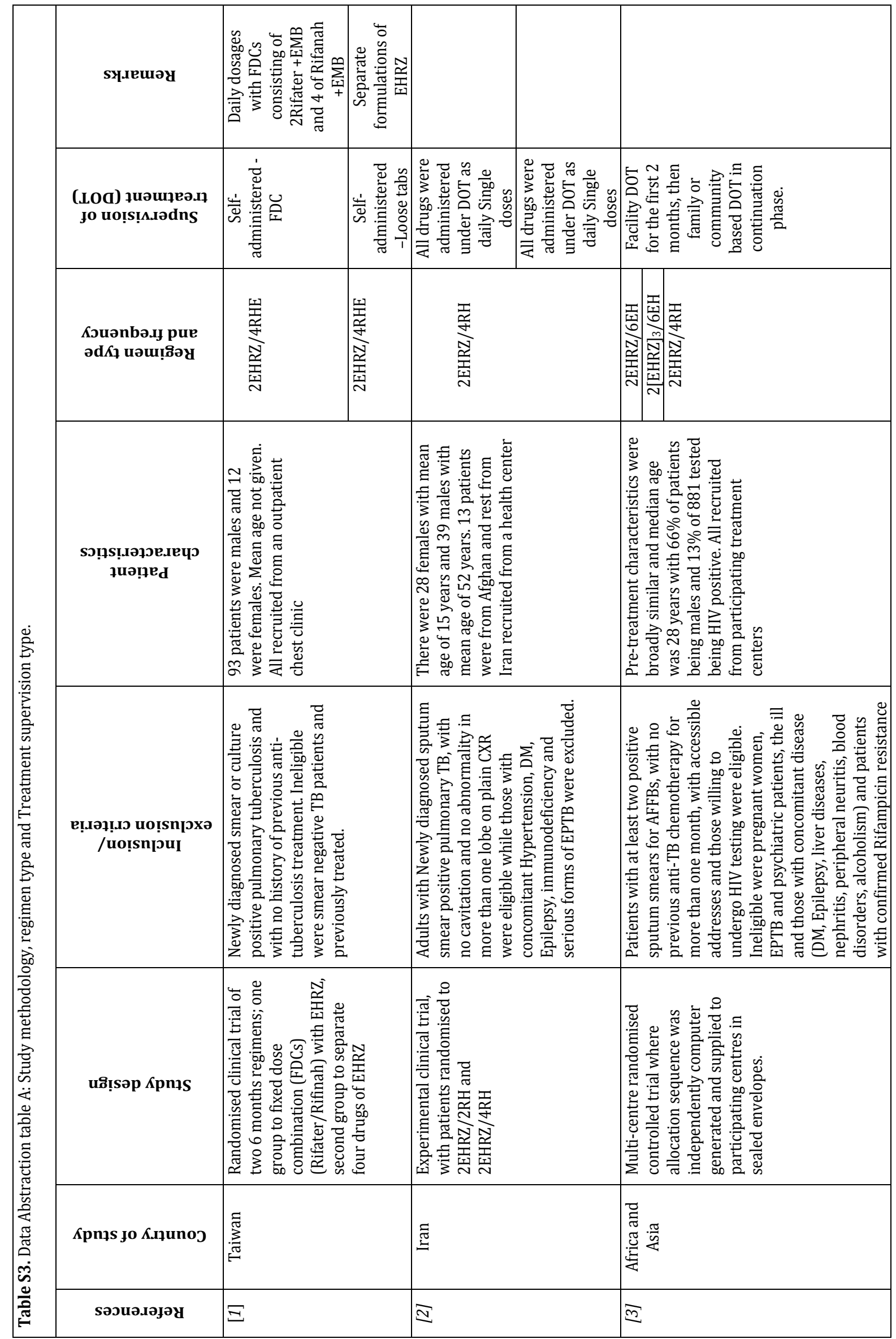




\begin{tabular}{|c|c|c|c|c|c|}
\hline 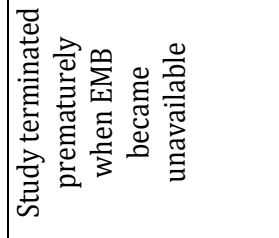 & & & 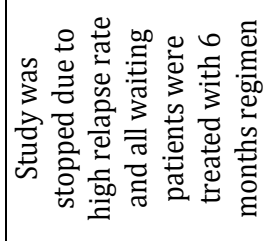 & 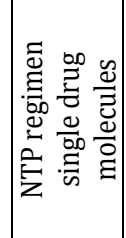 & 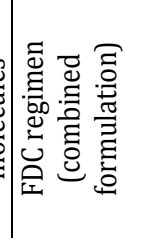 \\
\hline 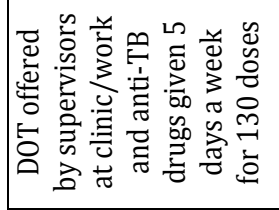 & Б용 & ๒ & 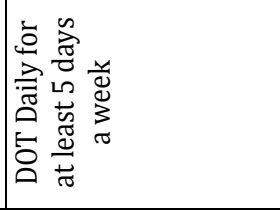 & Ë & E̊ \\
\hline 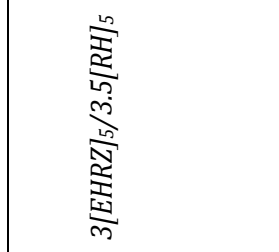 & 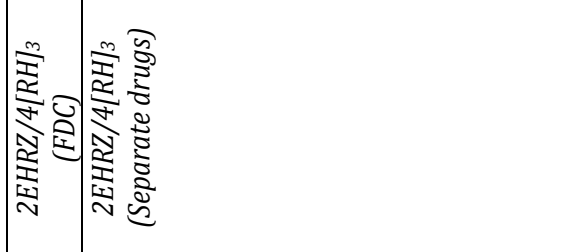 & 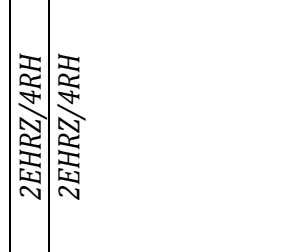 & 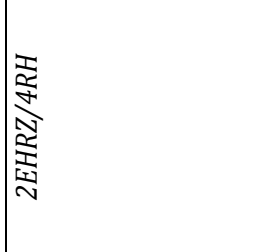 & 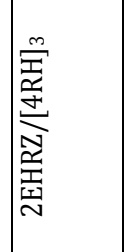 & 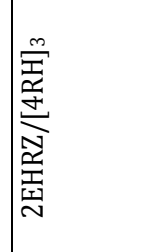 \\
\hline 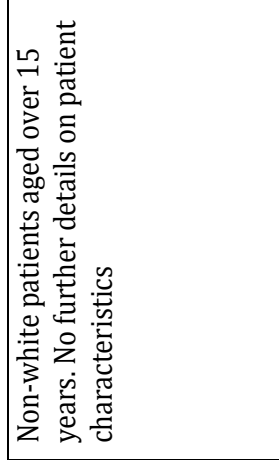 & 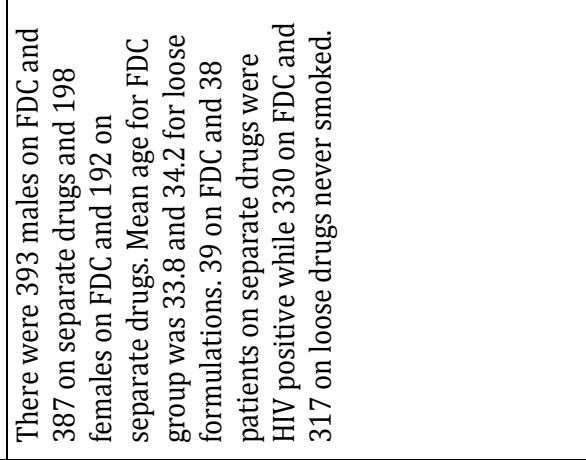 & 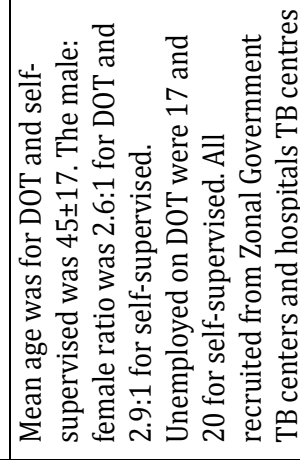 & 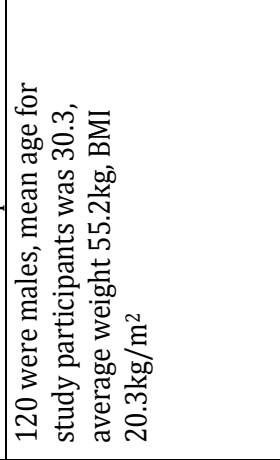 & \multicolumn{2}{|c|}{ 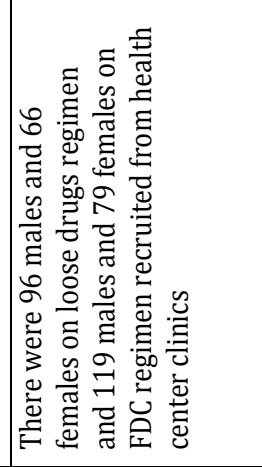 } \\
\hline 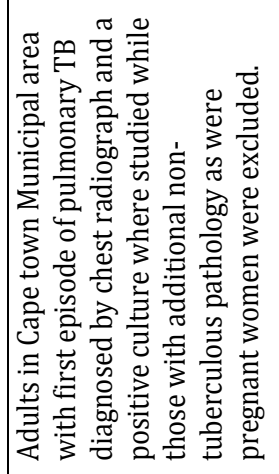 & 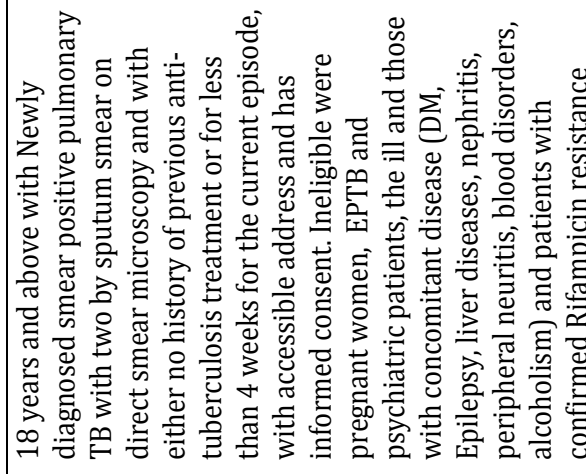 & 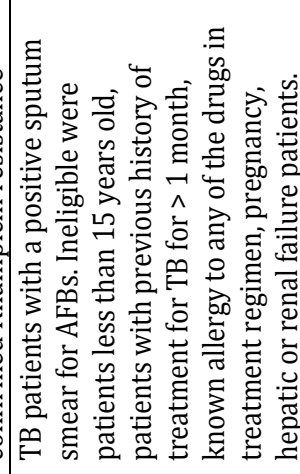 & 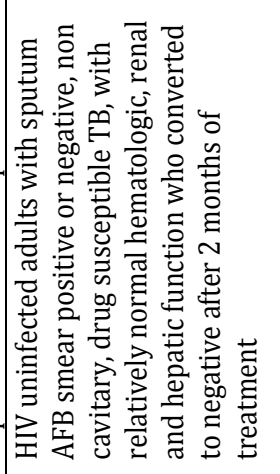 & \multicolumn{2}{|c|}{ 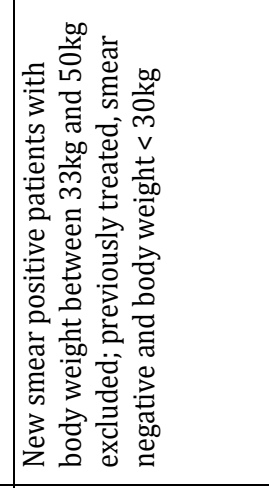 } \\
\hline 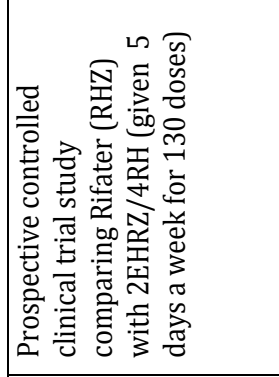 & 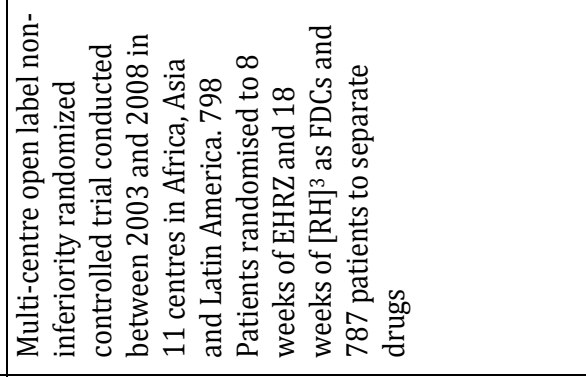 & 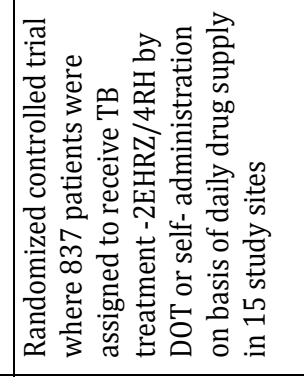 & 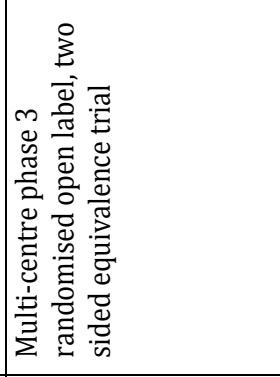 & \multicolumn{2}{|c|}{ 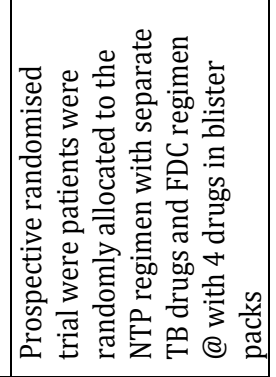 } \\
\hline 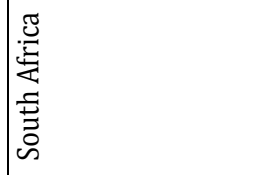 & 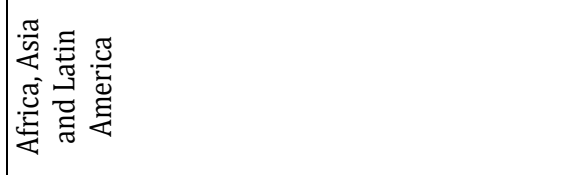 & 胥 & 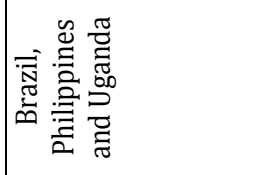 & 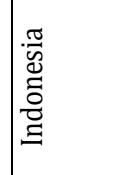 & \\
\hline$\underset{\nexists}{ }$ & $\sqrt{n}$ & 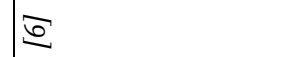 & $\mathbb{E}$ & $\infty$ & \\
\hline
\end{tabular}




\begin{tabular}{|c|c|c|c|c|}
\hline & & & 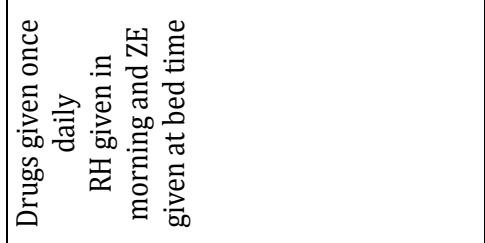 & \\
\hline 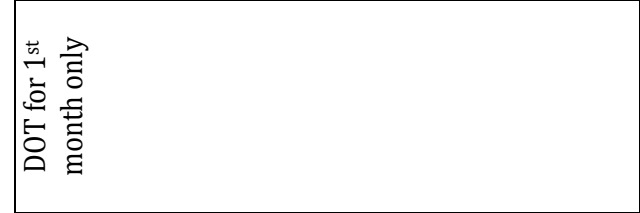 & 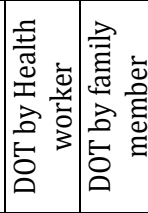 & 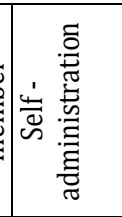 & 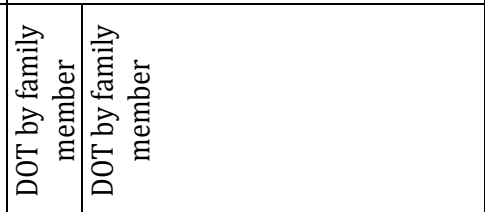 & 离 \\
\hline 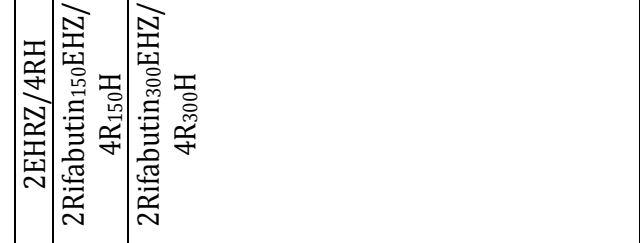 & 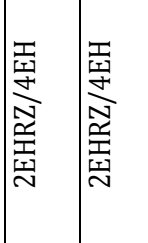 & 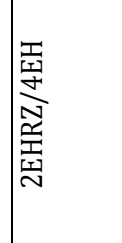 & 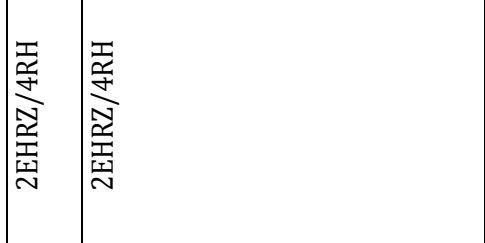 & 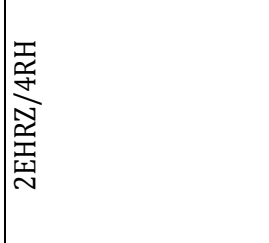 \\
\hline 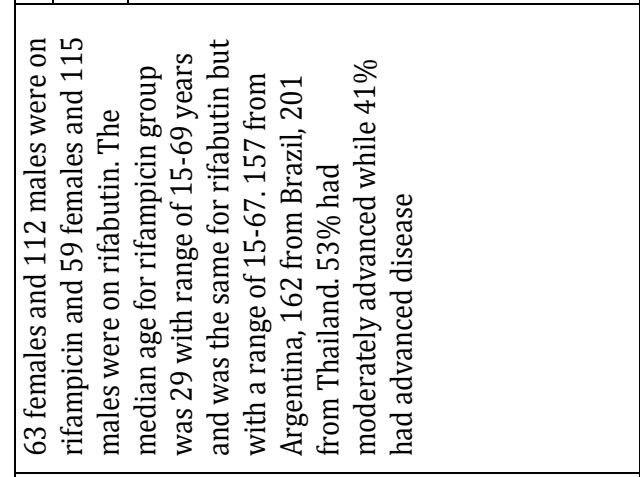 & 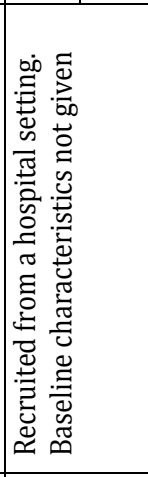 & & 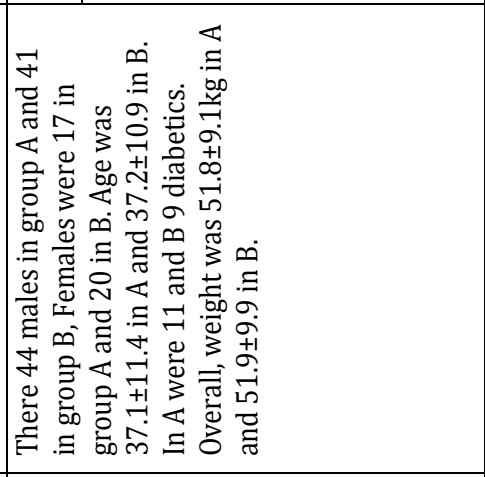 & 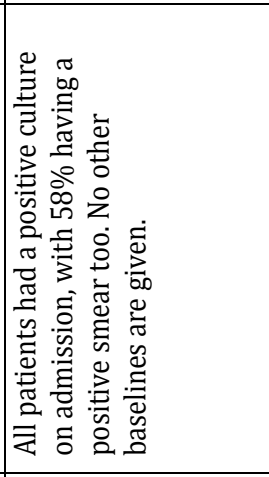 \\
\hline 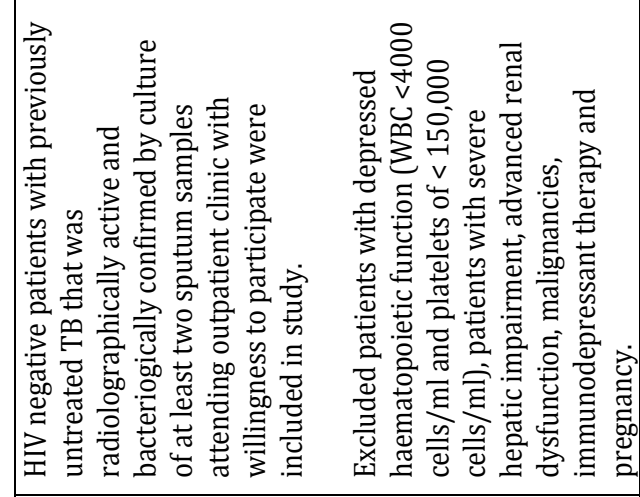 & 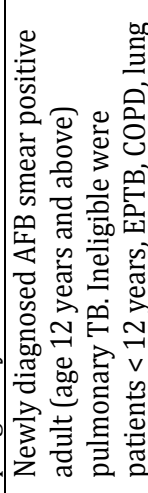 & 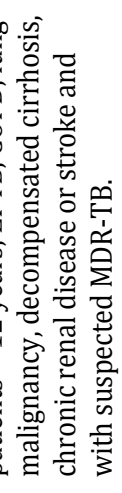 & 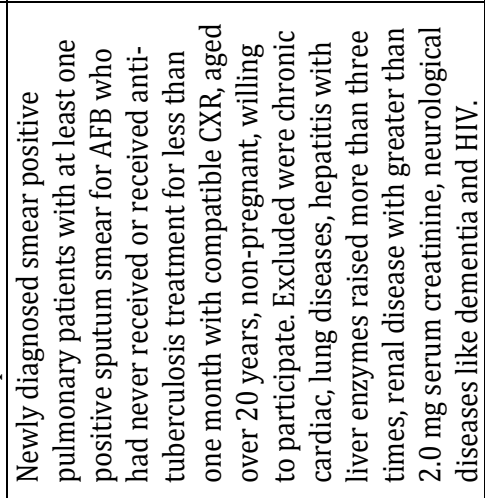 & 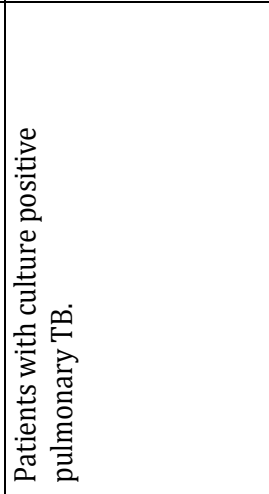 \\
\hline 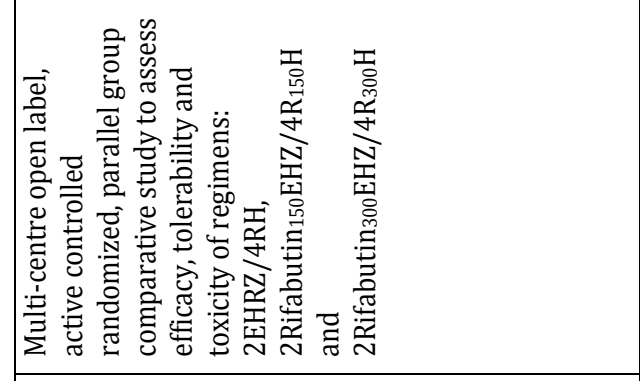 & 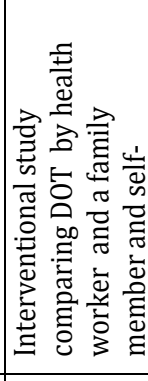 & & 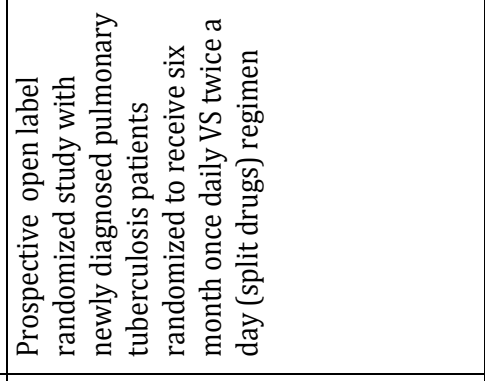 & 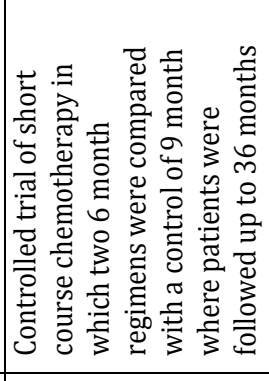 \\
\hline 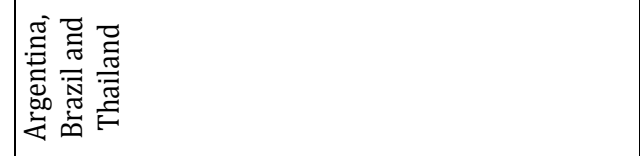 & & & $\mid$ & 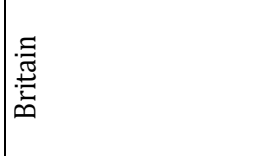 \\
\hline $\bar{\Omega}$ & $\Xi$ & & $\bar{\Xi}$ & $\Xi$ \\
\hline
\end{tabular}




\begin{tabular}{|c|c|c|c|}
\hline 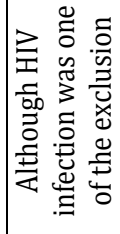 & 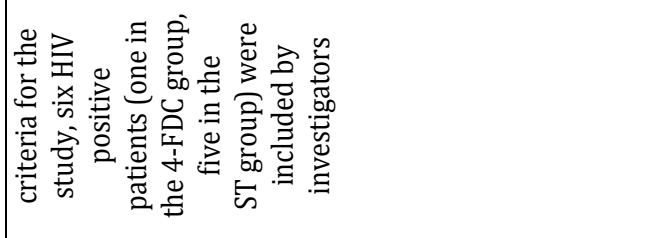 & & \\
\hline 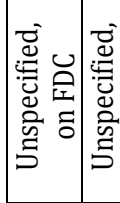 & 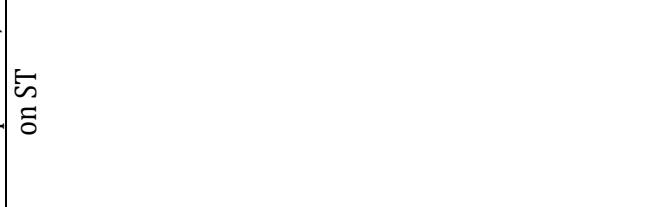 & 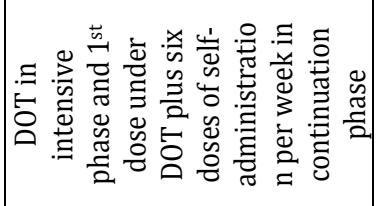 & 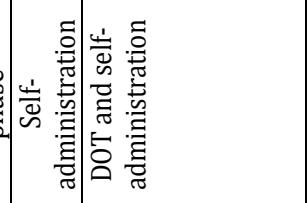 \\
\hline 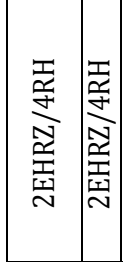 & & 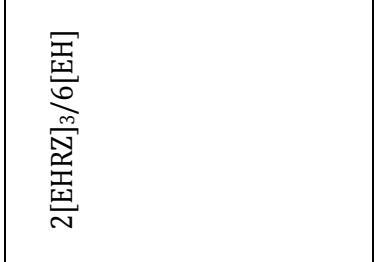 & 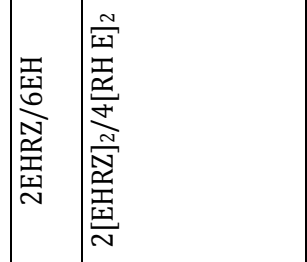 \\
\hline 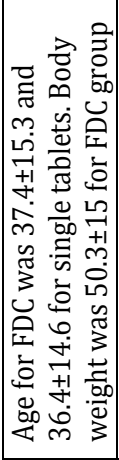 & 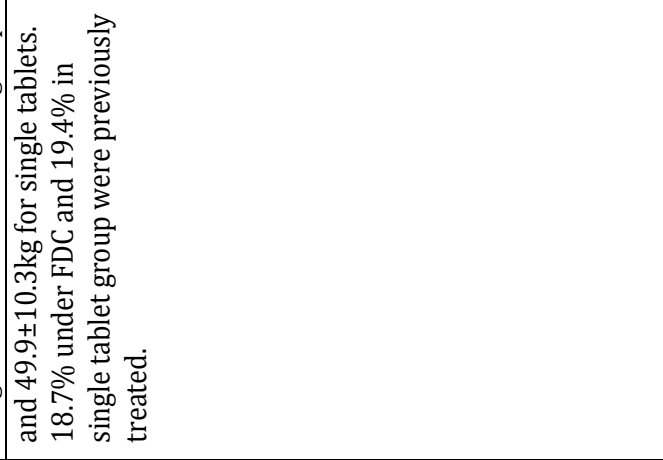 & 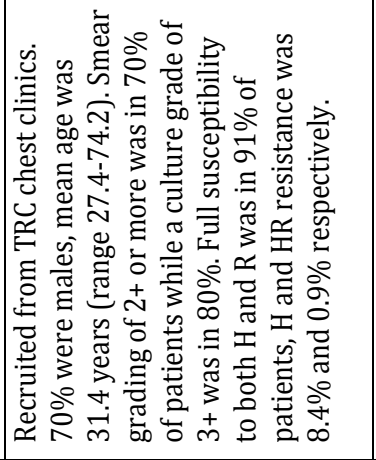 & 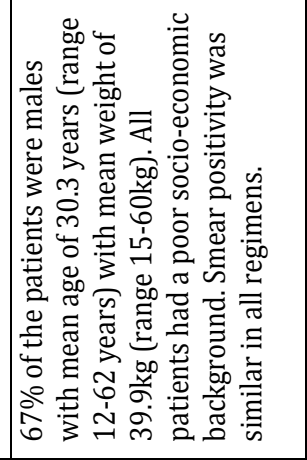 \\
\hline 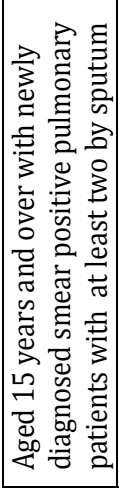 & 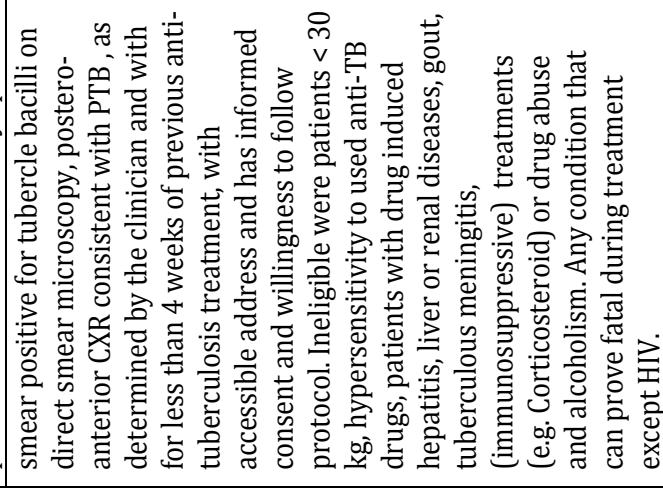 & 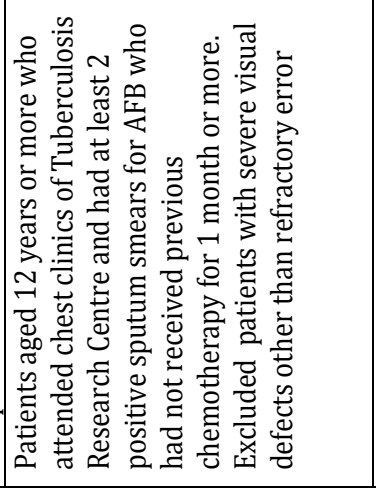 & 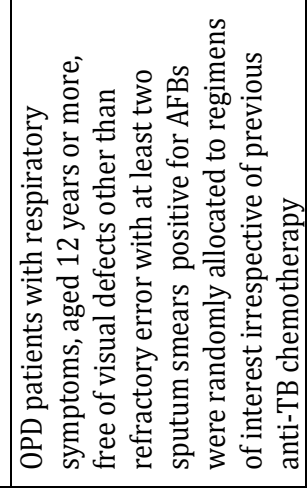 \\
\hline 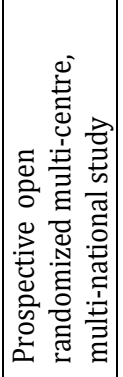 & 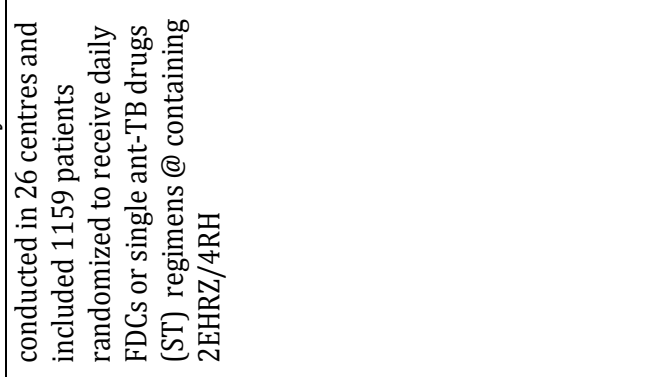 & 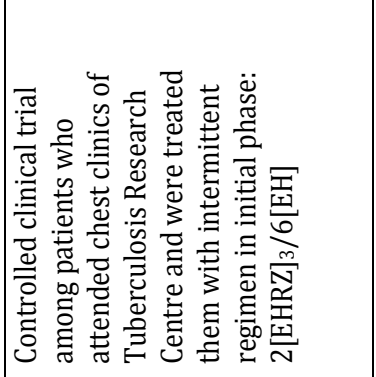 & 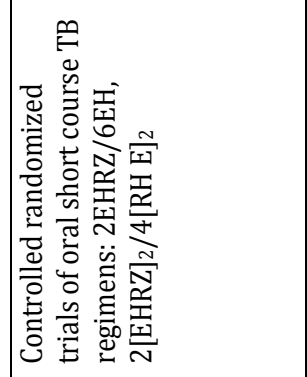 \\
\hline 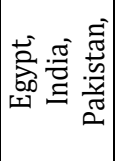 & 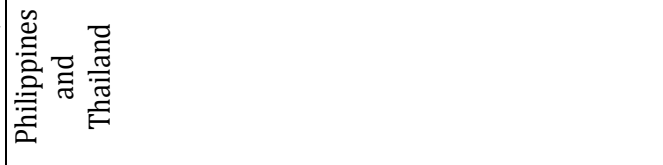 & 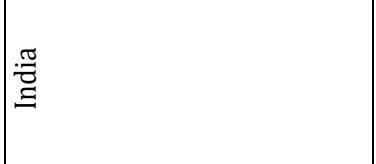 & : \\
\hline $\bar{m}$ & & $\underset{\Xi}{\Xi}$ & 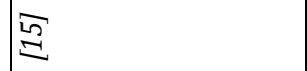 \\
\hline
\end{tabular}




\begin{tabular}{|c|c|c|c|c|c|c|c|c|}
\hline & 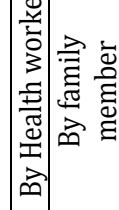 & 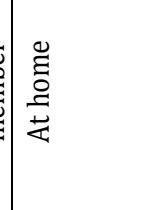 & 呈 & 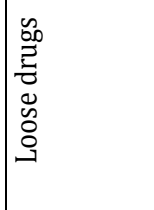 & & & & \\
\hline$\overline{8}$ & 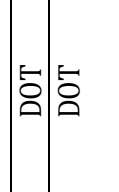 & (⿸丆口 & 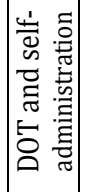 & 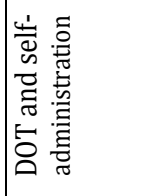 & E̊ & \begin{tabular}{|l|l}
$\bar{\circ}$ & $\bar{\circ}$
\end{tabular} & 駋 & 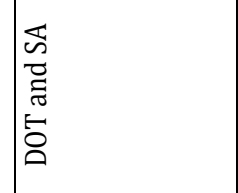 \\
\hline 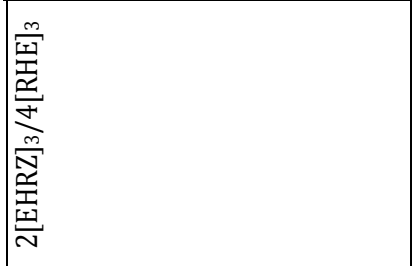 & 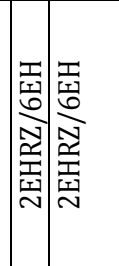 & 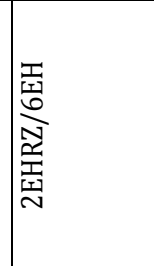 & 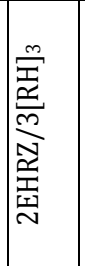 & 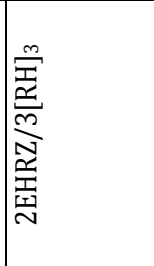 & 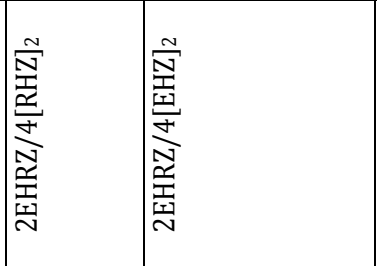 & 蛋空 & 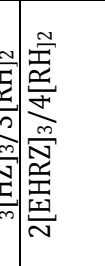 & 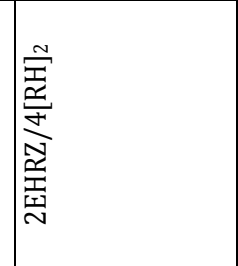 \\
\hline 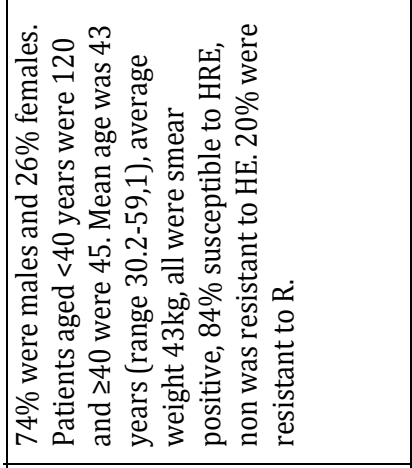 & 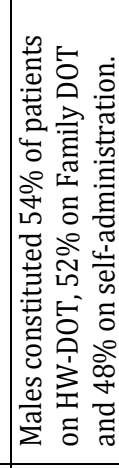 & 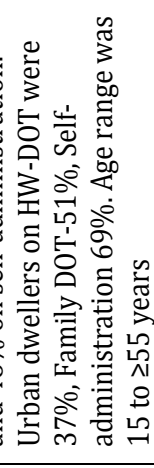 & 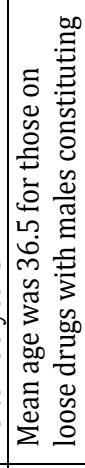 & 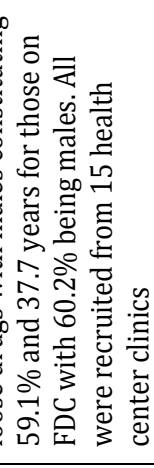 & 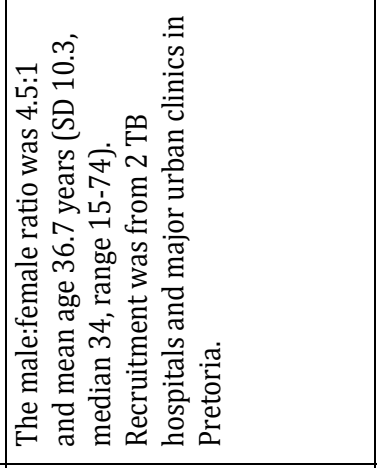 & 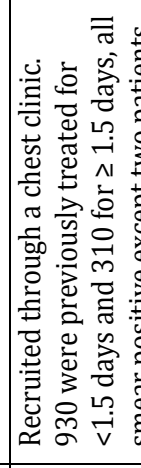 & 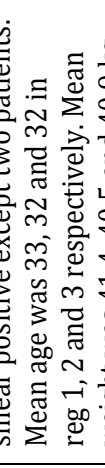 & 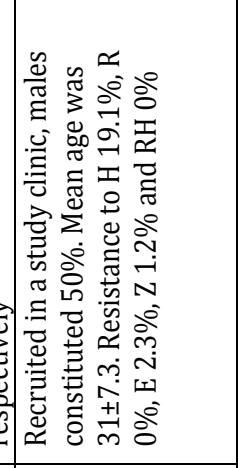 \\
\hline 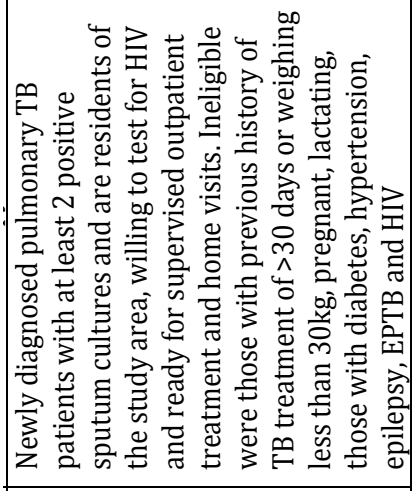 & 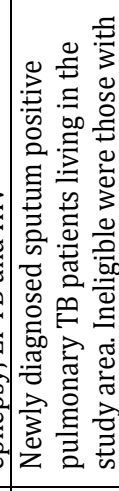 & 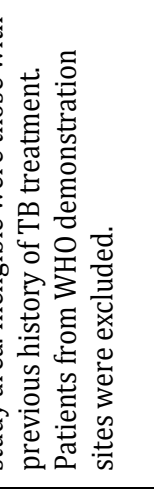 & 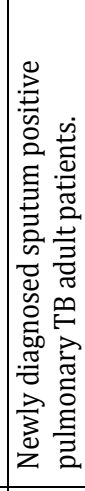 & 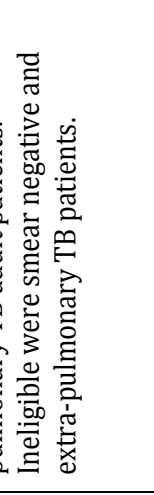 & 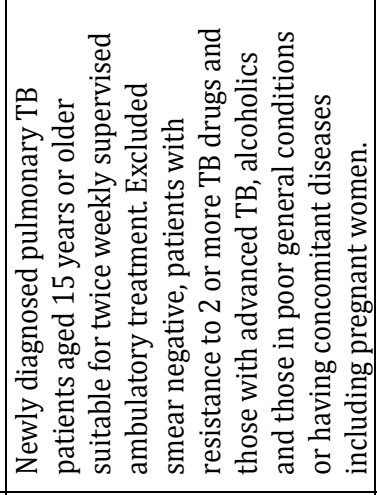 & 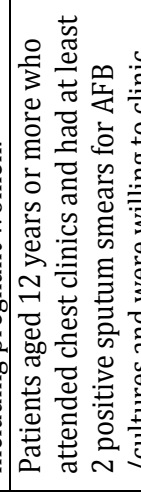 & 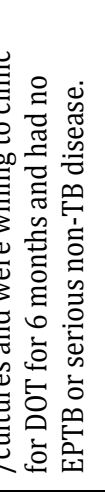 & 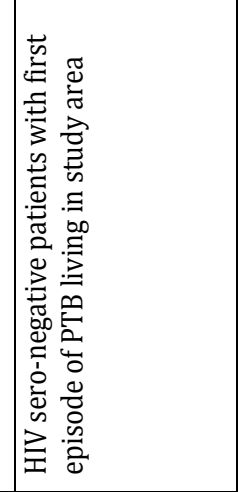 \\
\hline 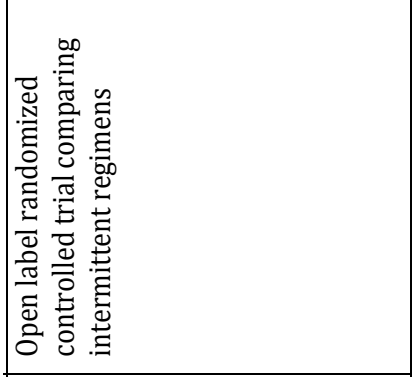 & 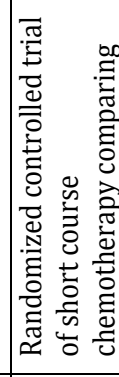 & 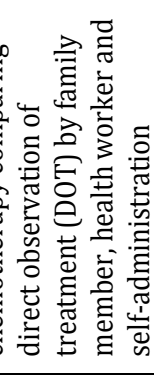 & 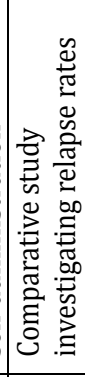 & 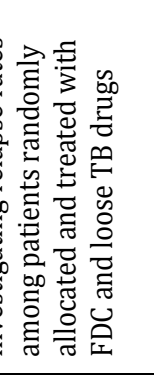 & 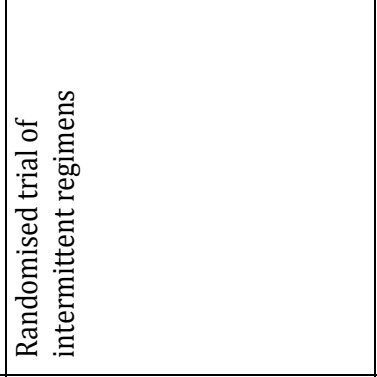 & 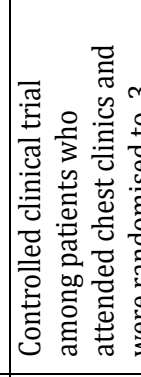 & 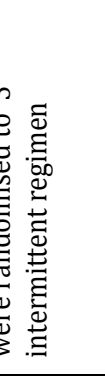 & 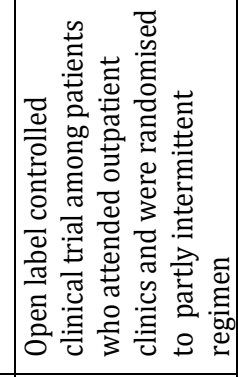 \\
\hline : & $\mid$ & & 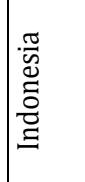 & & 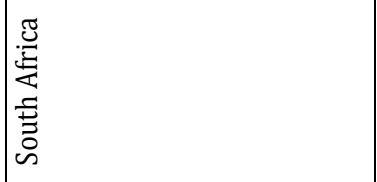 & 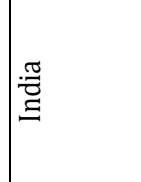 & & 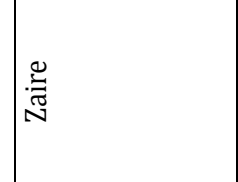 \\
\hline $\bar{\Xi}$ & $\underset{\Xi}{\mathbb{E}}$ & & $\stackrel{\infty}{=}$ & & $\bar{\Xi}$ & $\stackrel{\check{\Sigma}}{\check{\Sigma}}$ & & $\overline{\mathbb{Z}}$ \\
\hline
\end{tabular}




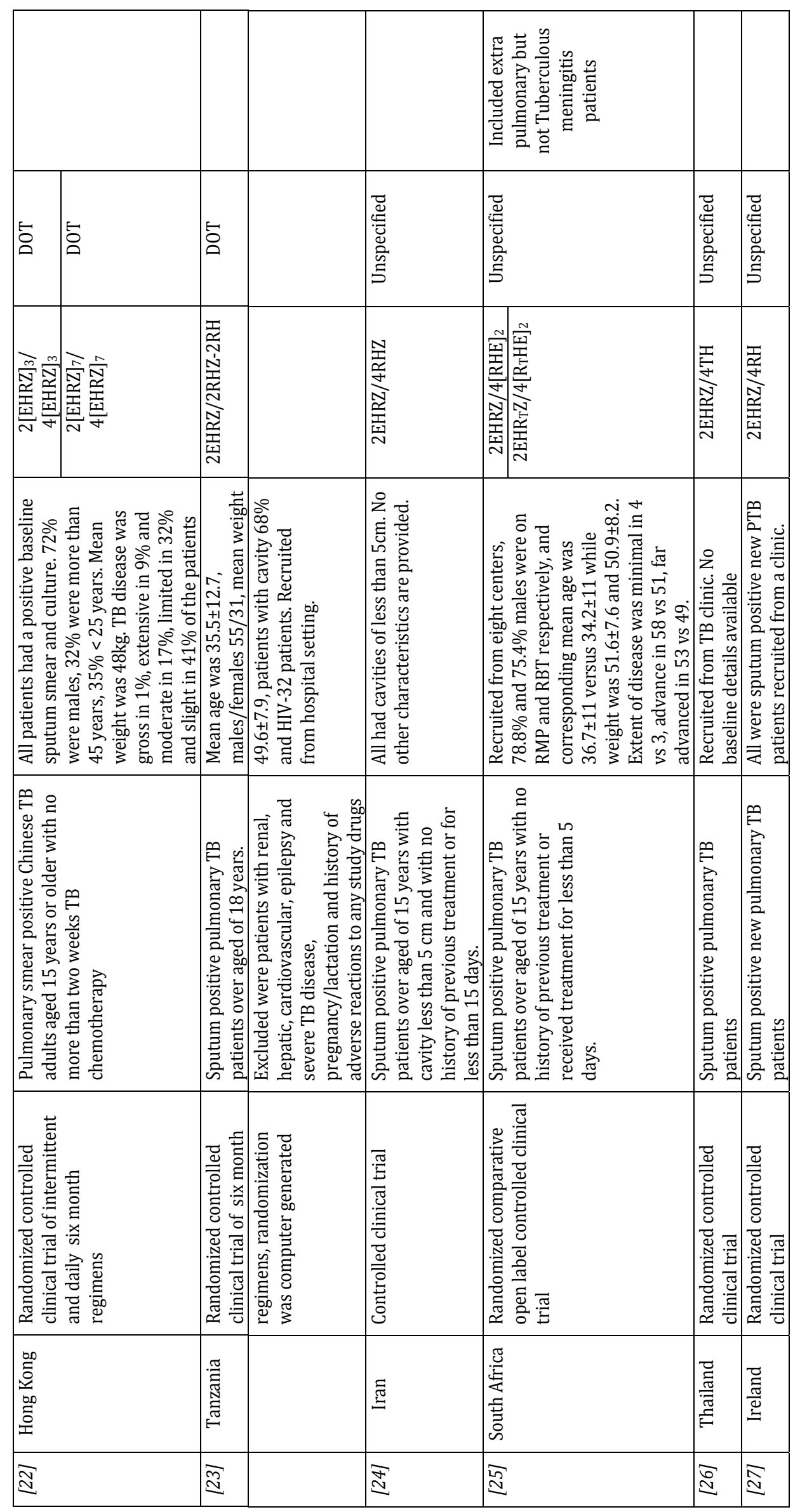




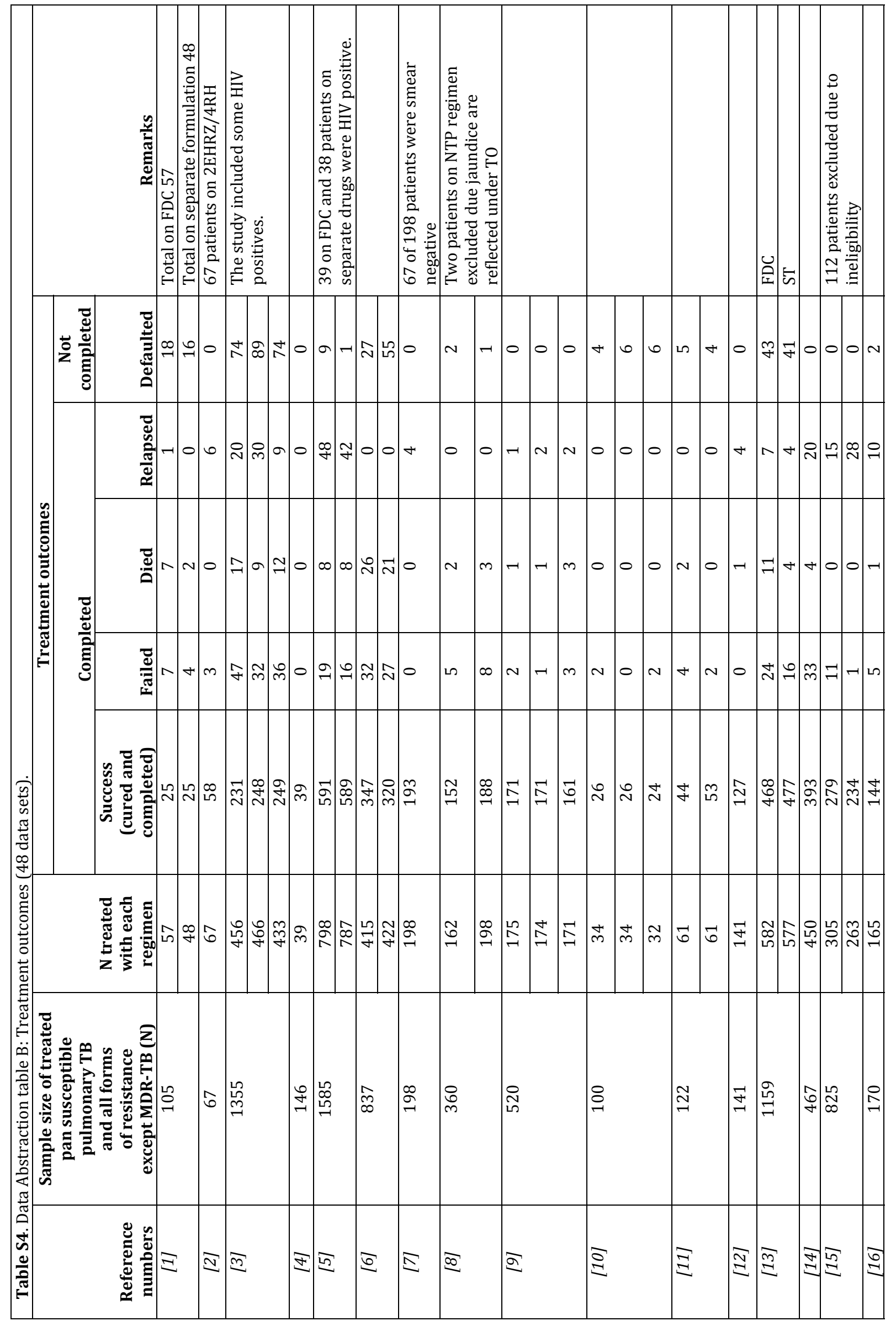




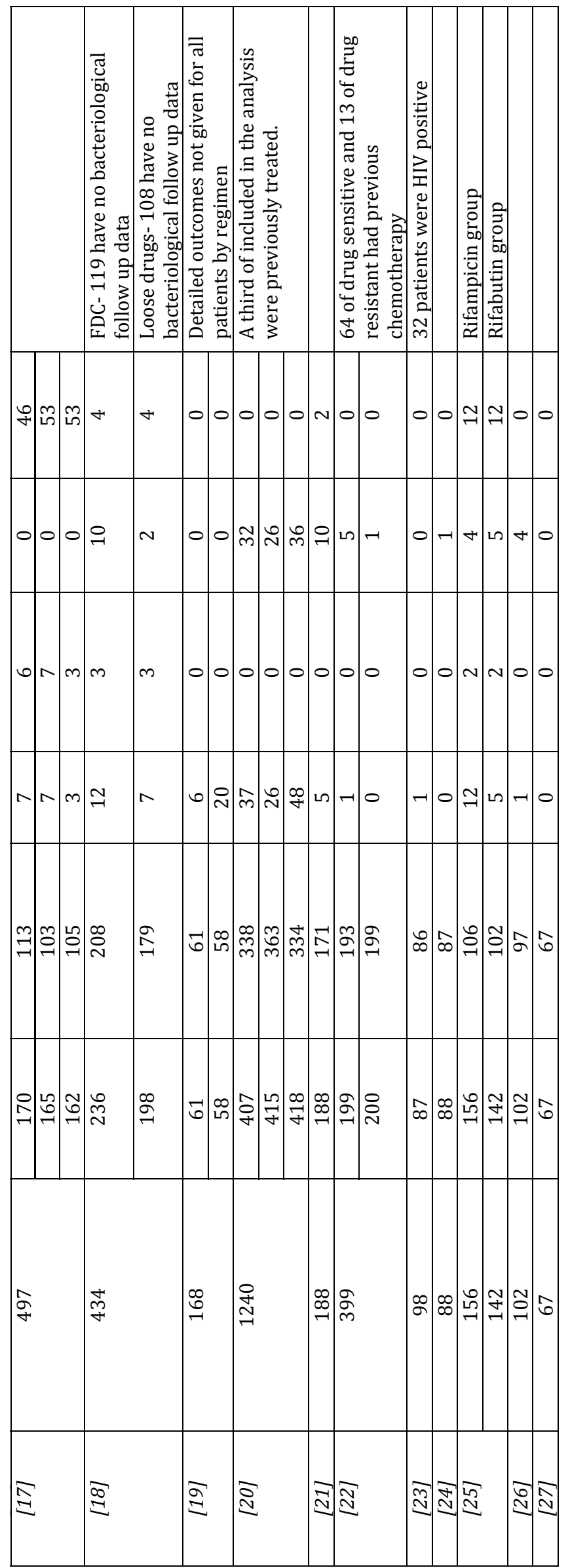




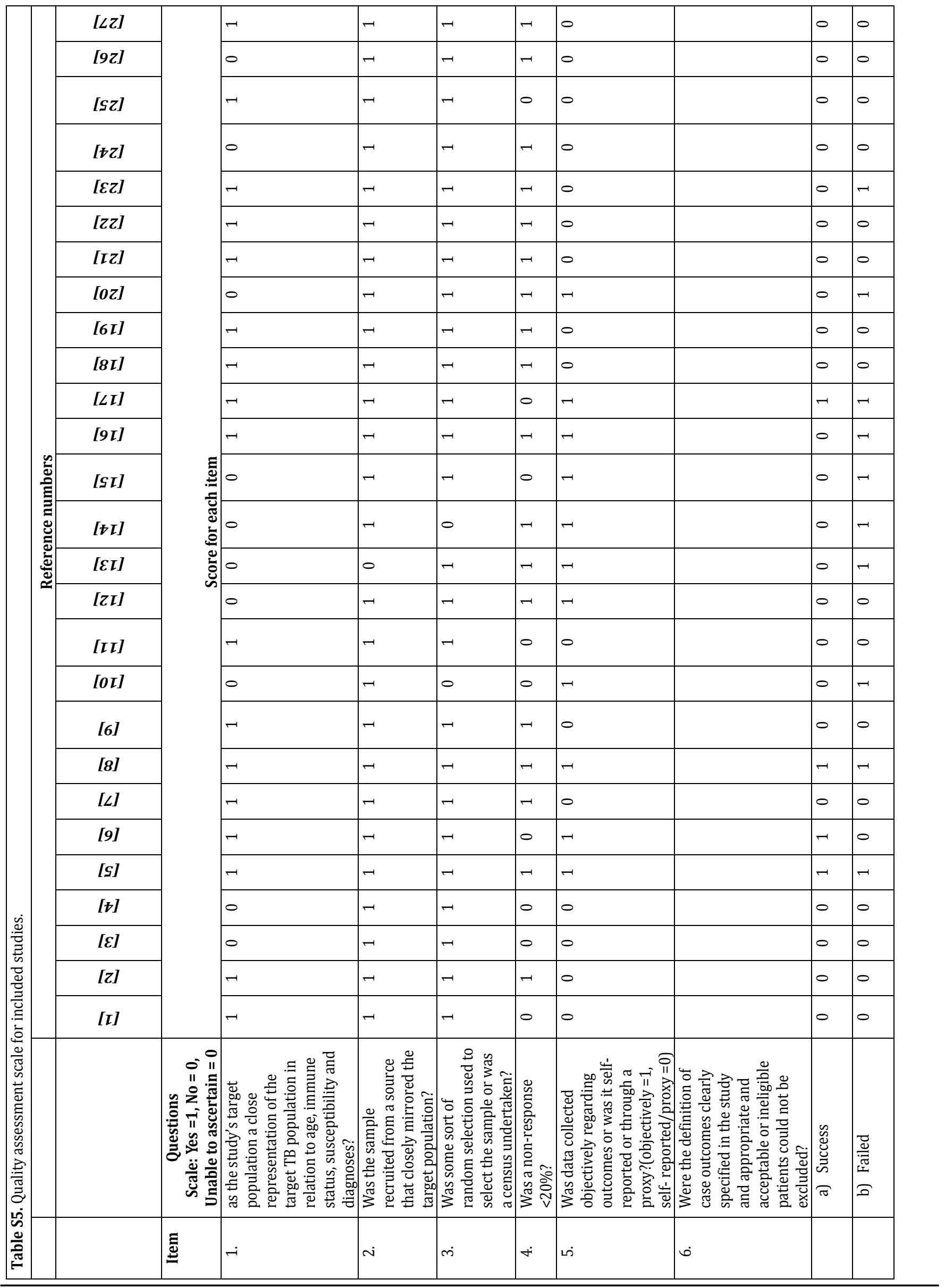




\begin{tabular}{|c|c|c|c|c|c|c|}
\hline 0 & 0 & - & 0 & -1 & 0 & 6 \\
\hline 0 & 0 & - & 0 & - & -1 & 6 \\
\hline 0 & 0 & $\neg$ & -1 & 0 & 0 & L \\
\hline 0 & 0 & 0 & 0 & -1 & -1 & Ln \\
\hline 0 & 0 & - & 0 & -1 & -1 & $\infty$ \\
\hline 0 & 0 & - & -1 & -1 & - & $\infty$ \\
\hline 0 & 0 & - & 0 & -1 & - & $r$ \\
\hline$\neg$ & 0 & $\neg$ & 0 & -1 & -1 & $a$ \\
\hline 0 & 0 & 0 & 0 & -1 & - & 0 \\
\hline- & 0 & 0 & 0 & -1 & - & $r$ \\
\hline- & $\rightarrow$ & $\neg$ & 0 & 0 & 0 & $a$ \\
\hline-1 & 0 & $\neg$ & - & - & - & $\exists$ \\
\hline$\neg$ & 0 & $\neg$ & 0 & -1 & -1 & $\infty$ \\
\hline-1 & 0 & - & - & - & - & $a$ \\
\hline 0 & 0 & - & - & - & -1 & $r$ \\
\hline$\dashv$ & 0 & - & 0 & - & - & $\infty$ \\
\hline 0 & 0 & - & - & - & 0 & 0 \\
\hline$\neg$ & - & - & 0 & 0 & 0 & 0 \\
\hline 0 & 0 & - & 0 & -1 & - & $r$ \\
\hline 0 & - & - & 0 & - & $\neg$ & $\exists$ \\
\hline 0 & 0 & $\neg$ & 0 & $\neg$ & $\neg$ & $\Lambda$ \\
\hline 0 & $\neg$ & $\neg$ & $\neg$ & $\neg$ & - & 음 \\
\hline$\neg$ & 0 & - & - & 0 & -1 & $\exists$ \\
\hline 0 & 0 & $\neg$ & 0 & 0 & 0 & $m$ \\
\hline 0 & 0 & $\neg$ & $\neg$ & 0 & -1 & in \\
\hline- & 0 & - & 0 & 0 & -1 & $r$ \\
\hline 0 & 0 & - & 0 & 0 & $\rightarrow$ & Lم \\
\hline \multirow[t]{2}{*}{ 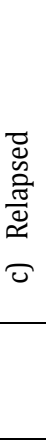 } & 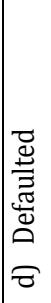 & 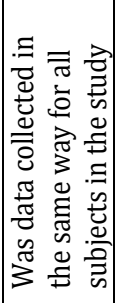 & 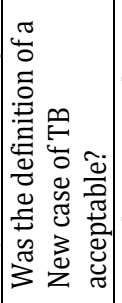 & 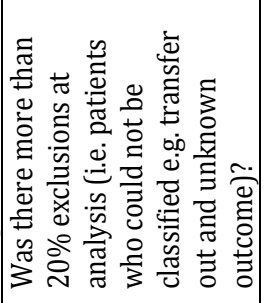 & 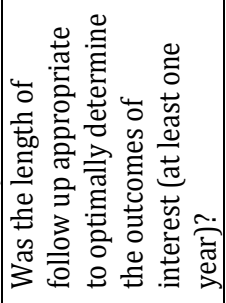 & 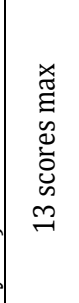 \\
\hline & & $\mathbf{N}^{\circ}$ & $\infty \infty^{\circ}$ & $\sigma^{\circ}$ & $\stackrel{\circ}{\circ}$ & 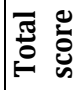 \\
\hline
\end{tabular}




\section{Supplementary References}

1. Su WJ, Perng RP. Fixed-dose combination chemotherapy (Rifater/Rifinah) for active pulmonary tuberculosis in Taiwan: a two-year follow-up. In J Tuberc Lung Dis 2002;6:1029-1032.

2. Sharifi-Mood B, Metanat M, Alavi-Naini R, Kouhpayeh HR, Salehi M, Naderi M, Hashemi-Shahri SM, Naser-Poor T. The comparison of six-month and four-month regimens of chemotherapy in the treatment of smear positive pulmonary tuberculosis. Journal of Medical Sciences 2006;6:108-111.

3. Nunn AJ, Jindani A, Enarson DA. Results at 30 months of a randomised trial of two 8-month regimens for the treatment of tuberculosis. In J Tuberc Lung Dis 2011;15:741-745.

4. Macnab MF, Bohmer PD, Seager JR. Evaluation of the 3-drug combination, Rifater, versus 4-drug therapy in the ambulatory treatment of tuberculosis in Cape Town. S Afr Med J 1994;84:325-328.

5. Lienhardt C, Cook SV, Burgos M, Yorke-Edwards V, Rigouts L, Anyo G, Kim SJ, Jindani A, Enarson DA, Nunn AJ; Study C Trial Group. Efficacy and safety of a 4-drug fixed-dose combination regimen compared with separate drugs for treatment of pulmonary tuberculosis: the Study $\mathrm{C}$ randomized controlled trial. JAMA 2011;305:1415-1423.

6. Kamol Ratanakul P, Sawert H, Lertmaharit S. Effectiveness of 'directly observed therapy, short course' (DOTS) in the treatment of pulmonary tuberculosis in Thailand [abstract]. J Clin-Epidemiol 1999; 52(Suppl 1):16s.

7. Johnson JL, Hadad DJ, Dietze R, Maciel EL, Sewali B, Gitta P, Okwera A, Mugerwa RD, Alcaneses MR, Quelapio MI, Tupasi TE, Horter L, Debanne SM, Eisenach KD, Boom WH. Shortening treatment in adults with noncavitary tuberculosis and 2-month culture conversion. Am J Respir Crit Care Med 2009;180:558-563.

8. Gravendeel JM, Asapa AS, Becx-Bleumink M, Vrakking HA. Preliminary results of an operational field study to compare side-effects, complaints and treatment results of a single-drug short-course regimen with a four-drug fixed-dose combination (4FDC) regimen in South Sulawesi, Republic of Indonesia. Tuberculosis (Edinburgh, Scotland) Vol. 83, 2003:183-186.

9. Gonzalez-Montaner LJ, Natal S, Yongchaiyud P, Olliaro P. Rifabutin for the treatment of newly-diagnosed pulmonary tuberculosis: A multinational, randomized, comparative study versus Rifampicin. Rifabutin Study Group. Tuber Lung Dis 1994;75:341-347.

10. Faisal AR, Qazi RA, Iqbal M, Waseemuddin J, Rehmani F, Bashir T. Effectiveness of directly observed treatment strategy (dots) as compared to self-administered therapy in tuberculosis. Ann Pak Inst Med Sci 2005;1:79-83.

11. Chuchottaworn C, Saipan B, Kittisup C, Cheewakul K. Adverse drug reactions and outcome of short course anti-tuberculosis drugs between single daily dose and split drug dose (BID) in pulmonary tuberculosis. J Med Assoc Thai 2012;95:S1-S5.

12. A controlled trial of 6 months' chemotherapy in pulmonary tuberculosis. Final report: results during the 36 months after the end of chemotherapy and beyond. British Thoracic Society. Br J Dis Chest 1984;78:330-336.

13. Bartacek A, Schutt D, Panosch B, Borek M; Rimstar 4-FDC Study Group. Comparison of a four-drug fixed-dose combination regimen with a single tablet regimen in smearpositive pulmonary tuberculosis. Int $\mathbf{J}$ Tuberc Lung Dis 2009;13:760-766.

14. Evaluation of a non-rifampicin continuation phase (6HE) following thrice-weekly intensive phase for the treatment of new sputum positive pulmonary tuberculosis. Indian J Tuberc 2007;54:84-90.
15. A controlled clinical trial of oral short-course regimens in the treatment of sputum-positive pulmonary tuberculosis. Tuberculosis Research Centre. Int J Tuberc Lung Dis 1997;1:509-517.

16. Jawahar MS, Banurekha VV, Paramasivan CN, Rahman F, Ramachandran R, Venkatesan P, Balasubramanian R, Selvakumar N, Ponnuraja C, Iliayas AS, Gangadevi NP, Raman B, Baskaran D, Kumar SR, Kumar MM, Mohan V, Ganapathy S, Kumar V, Shanmugam G, Charles N, Sakthivel MR, Jagannath K, Chandrasekar C, Parthasarathy RT, Narayanan PR. Randomized clinical trial of thrice-weekly 4-month moxifloxacin or gatifloxacin containing regimens in the treatment of new sputum positive pulmonary tuberculosis patients. PloS One 2013;8:e67030.

17. Walley JD, Khan MA, Newell JN, Khan MH. Effectiveness of the direct observation component of DOTS for tuberculosis: a randomised controlled trial in Pakistan. Lancet 2001;357:664-669.

18. Suryanto AA, van den Broek J, Hatta M, de Soldenhoff R, van der Werf MJ. Is there an increased risk of TB relapse in patients treated with fixed-dose combination drugs in Indonesia? Int J Tuberc Lung Dis 2008;12:174-179.

19. Felten MK. Importance of rifampicin in combined daily/ intermittent chemotherapy for tuberculosis. S Afr Med J 1989;75:524-526.

20. Santha T, Rehman F, Mitchison DA, Sarma GR, Reetha AM, Prabhaker R; ulosis Research Centre, Indian Council of Medical Research. Split-drug regimens for the treatment of patients with sputum smear-positive pulmonary tuberculosis-a unique approach. Trom Med Int Health 2004;9:551-558.

21. Perriens JH, St Louis ME, Mukadi YB, Brown C, Prignot J, Pouthier F, Portaels F, Willame JC, Mandala JK, Kaboto M, et al. Pulmonary tuberculosis in HIV-infected patients in Zaire. A controlled trial of treatment for either 6 or 12 months. N Eng J Med 1995;332:779-784.

22. Controlled trial of four thrice-weekly regimens and a daily regimen all given for 6 months for pulmonary tuberculosis. Lancet 1981;1:171-174.

23 Kennedy N, Berger L, Curram J, Fox R, Gutmann J, Kisyombe GM, Ngowi FI, Ramsay AR, Saruni AO, Sam N, Tillotson G, Uiso LO, Yates M, Gillespie SH. Randomized controlled trial of a drug regimen that includes ciprofloxacin for the treatment of pulmonary tuberculosis. Clin Infect Dis 1996;22:827-833.

24. Baba H, Shinkai A, Izuchi R, Azuma Y. [Long-term results of short-course chemotherapy of pulmonary tuberculosis (second study--A). Results up to 6 years after the end of treatment with 4-6 month chemotherapy of pulmonary tuberculosis.] Kekkaku 1987;62:329-339 [Article in Japanese.]

25. McGregor MM, Olliaro P, Wolmarans L, Mabuza B, Bredell M, Felten MK, Fourie PB. Efficacy and safety of rifabutin in the treatment of patients with newly diagnosed pulmonary tuberculosis. Am J Respir Crit Care Med 1996;154:14621467.

26. Punnotok J, Pumprueg U, Chakorn T. A comparison of two short course tuberculosis chemotherapy regimens, both using Rifater during an intensive phase, with a 3 year follow-up. J Med Assoc Thai 1995;78:298-304.

27. Howell F, O’Laoide R, Kelly P, Power J, Clancy L. Short course chemotherapy for pulmonary tuberculosis. A randomised controlled trial of a six month versus a nine month oral regimen. Ir Med J 1989;82:11-13. 